\title{
PLANEAMIENTO ESTRATÉGICO DE LA PRODUCCIÓN PETROLERA DE COLOMBIA 2013
}

\author{
MARIO ALEJANDRO ROSERO GUZMÁN
}

UNIVERSIDAD SANTO TOMÁS

FACULTAD DE ECONOMÍA BOGOTÁ, COLOMBIA

2014 



\section{PLANEAMIENTO ESTRATÉGICO DE LA PRODUCCIÓN PETROLERA DE COLOMBIA 2013}

\section{Mario Alejandro Rosero Guzmán}

Tesis o trabajo de investigación presentada(o) como requisito parcial para optar al título de Máster en Ciencias Económicas

Director: Gilberto Enrique Herazo Cueto Magister en Planeación Socioeconómica

UNIVERSIDAD SANTO TOMÁS

FACULTAD DE ECONOMÍA BOGOTÁ, COLOMBIA 2014 

Dedico esta tesis de Maestría en Ciencias Económicas a Dios por su iluminación, a la Virgen María por la paciencia, a Santo Tomás de Aquino, San Buenaventura y San Francisco de Asís patronos de los estudiantes, de la juventud y de la ecología, a mis Padres Luz Marina y Ancizar a quienes debo la vida y el espíritu, así como a mis hermosas Sandy, Emma y Sofi quienes me inspiraron y son mi fuerza para continuar. Por lo que puedo recordar y lo que no, por lo que me es sencillo plasmar en este documento y lo que me es difícil, polarmente con ayuda del caracol de Pascal $\rho=2 a \cdot \cos (w)+h$ : $h=2 a$ y el concoide de Nicomedes $\rho=\frac{b}{\cos (w)}+h: h=2 a: b=-2 a \cdot(\cos (w))^{2}$ a los cinco dedico este documento con todo mi $p=2 \mathbb{Q} a(\mathbb{1}-\cos (\mathbb{W}))$ 



\section{Agradecimientos}

Me gustaría agradecer sinceramente a mi tutor de tesis Gilberto Enrique Herazo Cueto por la sencillez y claridad en el enfoque de los temas sociales, a Ana María Torres Hernández por su apoyo metodológico y calidez humana, a Pedro Elías Galindo León especialista en temas asociados al sector de Hidrocarburos en Colombia, a Alejandro Vivas Benítez riguroso economista al igual que persona de impecable proceder y fino humor, a mis jurados Álvaro Andrés Vernazza Paez y Oscar Arcos Palma, todos ellos quienes gracias a sus conocimientos, orientaciones, persistencia, motivación, seriedad, responsabilidad y rigor académico se han ganado mi lealtad y admiración.

A Luz Marina, Ancizar, Sandra Lucia, Emma Lucia y Ariadna Sofía mi familia, para quienes no tengo léxico suficiente en expresar mi gratitud por todos sus sacrificios y apoyo que me permitieron llegar a ser quien soy.

Y como enfoque a las ciencias económicas finalmente he de agradecer a la Carta Encíclica Populorum Progressio de Giovanni Battista Enrico Antonio Maria Montini (Papa Pablo VI) enviada a los obispos, sacerdotes, religiosos y fieles de todo el mundo, así como a todos los hombres de buena voluntad, cuyo contenido asocia la necesidad de promover el desarrollo de los pueblos, y expresa tajantemente que la Paz no se reduce a una ausencia de la guerra, fruto del equilibrio siempre precario de las fuerzas, sino que se construye día a día en la instauración de un orden querido por Dios, que se compone de una justicia más perfecta entre los hombres, y es resumida en el justo desarrollo económico de los pueblos del mundo. 


\section{Resumen}

La evaluación de la situación estratégica de la producción petrolera en Colombia, la cual se evaluará en el año 2013, muestra que se trata de un sector vinculado tanto a lo público como a lo privado, teniendo una repercusión destacada en la economía del país. La importancia de esta fuente de energía no solamente es relevante para Colombia sino que a nivel mundial las grandes potencias del mundo muestran una gran dependencia de la evolución de los precios y de las reservas del petróleo, debido a que sigue siendo la fuente principal de energía para mover todas las empresas e industrias algunas tan críticas como el transporte.

Si bien los precios internacionales en 2008 estaban muy cerca del nivel que tuvieron treinta años atrás, después de haber experimentado fuertes caídas al comienzo de los 80 y acelerados incrementos a comienzo del Siglo XXI, en los últimos tres años esos precios se han vuelto a incrementar, como consecuencia de la incertidumbre asociada al comportamiento de la economía mundial derivada de los eventos geopolíticos, choques de demanda en mercados emergentes, de la lenta recuperación de la demanda de los países industrializados y la volatilidad de los mercados financieros. Esta evolución muestra la estrecha relación que tienen los fenómenos económicos globales y los precios del petróleo.

En Colombia en los últimos años se ha presentado un acelerado crecimiento de la inversión extranjera directa, como consecuencia de la modificación de los sistemas de contratación y de la creación de la Agencia Nacional de Hidrocarburos, lo que permite ver con optimismo la evolución de esta industria en los próximos años.

Palabras clave: Petróleo, economía, análisis estratégico. 


\section{Abstract}

The assessment of the strategic situation of petroleum production in Colombia shows that it is a linked to both public and private sector and has a prominent impact on the economy sector. The importance of this source of energy is something that happens not only in Colombia but worldwide the great powers are highly dependent on the evolution of prices and petroleum stocks, as is still the main source for moving companies and industries as critical as transportation.

While international prices in 2008 were close to the level they had thirty years ago, after experiencing sharp declines in the early 80 s and accelerated increments beginning of XXI century, in the last three years these prices have increased again as a result of the uncertainty associated with the performance of the world economy stemming from geopolitical events, the demand growth in emerging markets, the slow recovery of demand in industrialized countries and the volatility of financial markets. This evolution shows the close relationship between global economic events and oil prices.

In Colombia in recent years has presented a rapid growth of foreign direct investment as a result of changes in procurement systems and the creation of the National Hydrocarbons Agency, allowing for optimism about developments in the industry in the coming years.

Keywords: Petroleum, economics, strategic analysis. 


\section{Contenido}

Pág.

Resumen

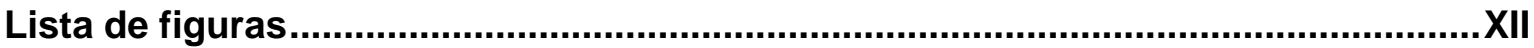

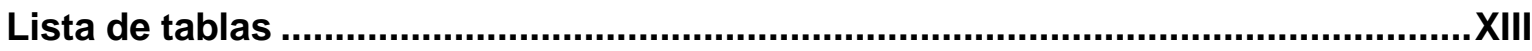

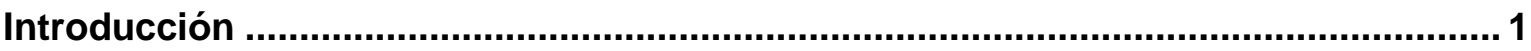

1. ALCANCE DE LA INVESTIGACIÓN Y ANTECEDENTES …...................................

$1.1 \quad$ Alcance de la investigación......................................................................

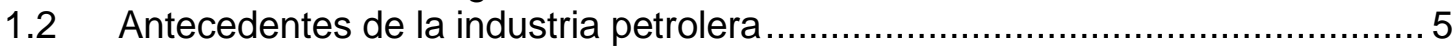

2. FACTORES EXTERNOS QUE INTERVIENEN EN LA PRODUCCIÓN PETROLERA

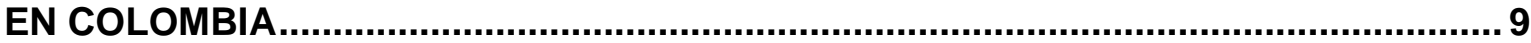

2.1 Situación geopolítica............................................................................... 10

2.2 Demanda externa de petróleo ..................................................................... 11

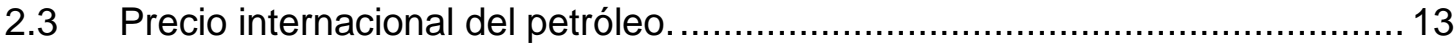

2.4 Factores propios de la industria petrolera. .............................................. 19

2.5 Matriz de evaluación de factores externos - MEFE ................................... 23

\section{FACTORES INTERNOS QUE INTERVIENEN EN LA PRODUCCIÓN PETROLERA}

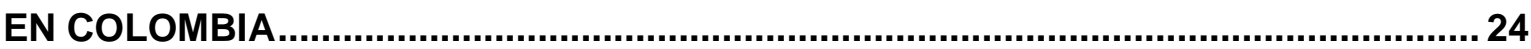

3.1 Situación geopolítica y legislativa. .........................................................2

3.2 Factores propios del sector...................................................................... 31

3.3 El sector industrial y sus competidores. ................................................... 33

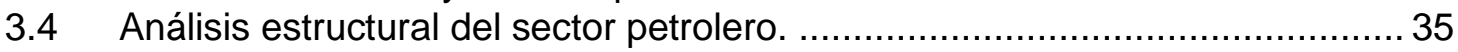

3.4.1 Poder de negociación de los proveedores.........................................36

3.4.2 Poder de negociación de los compradores........................................37

3.4.3 Amenaza de los productos sustitutos del petróleo..................................38

3.4.4 Ingreso potencial de competidores al mercado. .................................. 39

3.4.5 Rivalidad entre las compañías competidoras. .................................. 40

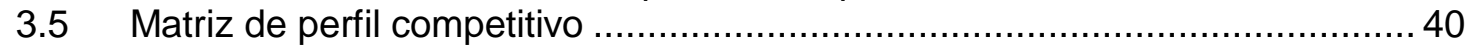

3.6 Evolución del sector en los años 2010 a 2012 ......................................... 42

3.6.1 Entorno internacional. ......................................................... 42

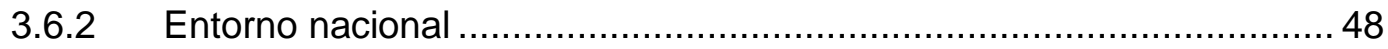

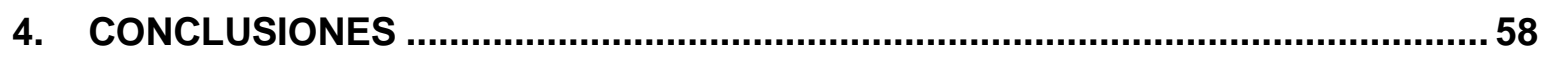

Bibliografía 


\section{Lista de figuras}

Pág.

Figura 2-1: Vínculos del sector petrolero con la economía nacional..............................

Figura 2-2: Precios promedio anuales del petróleo WTI (1979-2008)............................ 15

Figura 2-3. Precio Diario del Petróleo WTI (2008-2014) ........................................... 17

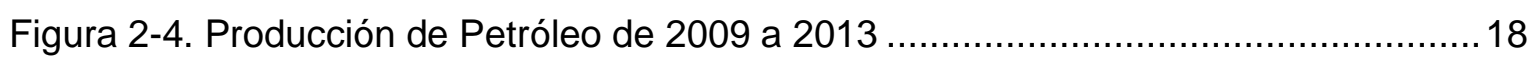

Figura 3-1. Determinantes de la producción de Hidrocarburos en el país. ......................25

Figura 3-2. Participación del sector minero y petrolero en el PIB de Colombia..................34

Figura 3-3. Participación del sector minero y petrolero en el PIB de Colombia..................34

Figura 3-4. Proyección del consumo mundial de energía primaria .................................43

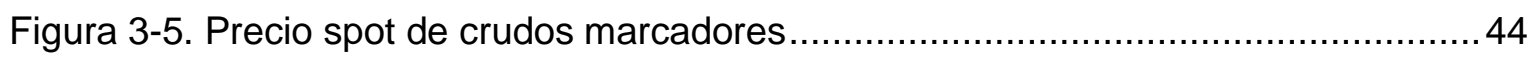

Figura 3-6. Evolución de las reservas mundiales de petróleo.......................................... 45

Figura 3-7. Producción mundial diaria de petróleo …………......................................... 46

Figura 3-8. Reservas probadas de petróleo Centro y Suramérica...................................4

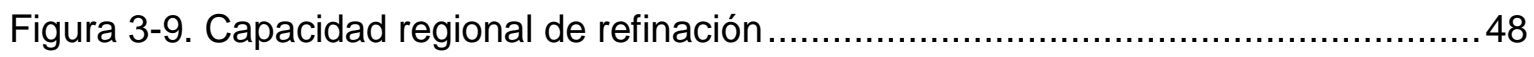

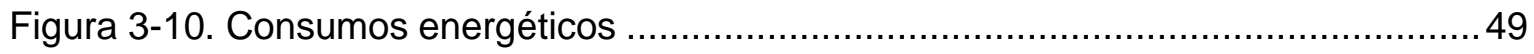

Figura 3-11. Inversión extranjera directa en petróleos...............................................50

Figura 3-12. Evolución de contratos de actividad sísmica ........................................... 51

Figura 3-13. Reservas probadas de petróleo en Colombia ……....................................52

Figura 3-14. Evolución de la producción colombiana de petróleo.....................................53

Figura 3-15. Campos productores con producción mayor a 10.000 BPD .........................54

Figura 3-16. Exportaciones e importaciones de petróleo...................................................5

Figura 3-17. Evolución de las exportaciones de petróleo ……………….........................56 


\section{Lista de tablas}

Pág. Tabla 2-1. Matriz de Evaluación de Factores Externos del Sector Petrolero de Colombia

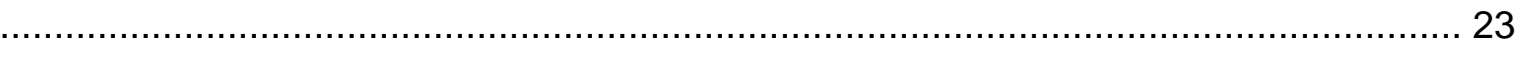

Tabla 3-1. Matriz del Perfil Competitivo del Sector Petrolero en Colombia .................... 41 



\section{Introducción}

El trabajo busca evaluar la situación estratégica de la producción petrolera en Colombia en el año 2013, dada la importancia que este subsector representa para toda la economía del país. Para hacer esa evaluación se toman en cuenta los factores externos que inciden en la situación de este subsector de la industria petrolera, teniendo en consideración que existen situaciones geopolíticas y comerciales de otros países que afectan el precio del petróleo. Así mismo se consideran los factores internos, especialmente los relacionados con políticas públicas sobre tasa de cambio y otros aspectos tributarios y de política económica, ambiental y minera en general que pueden implicar efectos para la producción petrolera.

Igualmente se consideran como parte fundamental del análisis los intereses y los objetivos que tiene este sector económico para el largo plazo, en cabeza tanto del Ministerio de Minas y Energía, como del Ministerio de Hacienda y de Ecopetrol, principalmente. Por último se analiza el cuadro de mando integrado (balance score card) de este subsector para conocer la forma como los diferentes factores previamente estudiados se interrelacionan.

El trabajo se encuentra organizado en tres capítulos; en el primeo se delimita el alcance de la investigación y se presentan los antecedentes de la industria petrolera, en el segundo se analizan los factores externos que intervienen en la producción de petróleo en el país y en el tercero los factores internos que intervienen en esta industria. 



\section{ALCANCE DE LA INVESTIGACIÓN Y ANTECEDENTES}

\subsection{Alcance de la investigación}

El resurgimiento de la industria petrolera en Colombia se da en el año 2003 a través del decreto 1760 del mismo año, en la cual se apuntalaron las bases para la restructuración del sector de hidrocarburos creando condiciones legales y técnicas para atraer la inversión; sin embargo, todos estos cambios administrativos no hubieran tenido mayor efecto sin la política de seguridad democrática que entró en vigencia el 7 de Agosto de 2002 puesta en marcha por el entonces presidente de Colombia doctor Alvaro Uribe Vélez, la cual tuvo como objetivo general reforzar y garantizar el Estado de Derecho en todo el territorio, mediante el fortalecimiento de la autoridad democrática: del libre ejercicio de la autoridad de las instituciones, del imperio de la ley y de la participación activa de los ciudadanos en los asuntos de interés común, siendo una de sus bases la protección de la infraestructura económica a través del desarrollo de programas especiales para prevenir los ataques terroristas contra la infraestructura carbonífera, eléctrica, petrolera, de puertos y aeropuertos y de telecomunicaciones, así como para prevenir el robo de hidrocarburos, mediante el trabajo coordinado en estructuras de apoyo del Ejército, la Fiscalía, el DAS, la DIJIN y la Procuraduría, con el apoyo de la ciudadanía, uno de estos programas fue el de la promoción del uso correcto de las regalías generadas por las actividades mineras y petroleras y de la inversión social de las empresas, para mejorar la calidad de vida de la comunidad, por medio de esta política se logró recuperar el control, tranquilidad y confianza de la gran mayoría de zonas que son típicamente las utilizadas por la industria petrolera para adelantar procesos de sísmica y exploración. El éxito de la política de seguridad democrática y la entrada en vigencia del mencionado decreto claramente lograron recuperar la confianza inversionista y han dinamizado la industria en general. Podemos también resaltar el precio internacional del crudo que en el año 2008 llegó a niveles de los USD150 el barril haciendo que las diferentes compañías petroleras entraran en mercados antes nunca imaginados. El 
decreto anteriormente mencionado distribuye las funciones entre diferentes entidades del gobierno: 1) Ministerio de Minas y Energía es el encargado de establecer las políticas; 2) La Agencia Nacional de Hidrocarburos ANH, creada a través del decreto 1760 en el año 2003, administra los recursos de hidrocarburos del país quitándole esta responsabilidad a la empresa de petróleos estatal Ecopetrol; 3) Ecopetrol se concentraría exclusivamente en actividades de exploración y explotación.

Las estadísticas ratifican el éxito de la implementación de la política y el decreto, que han catapultado los estudios de sísmica realizados en el país, los territorios dedicados a la exploración y explotación de hidrocarburos crecieron en más del 300\% y las cantidades exportadas llegando a niveles de más de 945.000 barriles por día en 2012 y tranzando como meta del marco estratégico de Ecopetrol, la producción de un millón de barriles limpios equivalentes de crudo al 2015, al mismo tiempo que proyecta un mayor esfuerzo para llegar a 1,3 millones de barriles equivalentes en 2020, significando estos "barriles limpios" producción sin accidentes e incidentes ambientales, así como en armonía con los grupos de interés, cifra que será fácilmente superada de mantenerse el ritmo de crecimiento que presenta el sector.

Según la Administración de Información Energética de los Estados Unidos, Colombia se ubica hoy en el puesto 22 de la lista de productores de petróleo en todo el mundo en el año 2012 y sigue ganando terreno de manera decidida, mientras que países como Venezuela se encuentran cediendo puestos como consecuencia de la disminución de su producción petrolera y equivocada política de inversión extranjera. Hoy Colombia cuenta con más de un centenar de empresas multinacionales y nacionales, las cuales se encuentran vinculadas en la exploración y producción de petróleo y esto gracias a los cambios estructurales implementados en los últimos años.

Para la economía nacional, el petróleo constituye un aspecto crítico dado su creciente impacto sobre la generación de divisas y, por lo tanto, sobre la situación de la balanza de pagos, al igual que sobre el manejo del déficit fiscal; si a esto se le agrega la generación 
de empleo, se puede concluir que ese impacto no es solamente económico sino también de orden social, haciendo que la situación de ese sector tenga una enorme incidencia, tanto en las finanzas públicas como en la industria privada la cual le provee insumos y le presta servicios.

Sin embargo, al mismo tiempo que se trata de una situación privilegiada, la sensibilidad y dependencia que presenta toda la situación económica del país, respecto de lo que pueda suceder en las futuras variaciones del precio internacional del barril de petróleo, lo cual en un alto riesgo en caso de presentarse circunstancias que amenacen la flexibilidad tecnológica de los niveles de producción Colombianos, en vista que se resentirían tanto las finanzas públicas, el sector privado, así como la inversión extranjera directa.

Dadas estas circunstancias y teniendo en cuenta que esta industria está compuesta por tres subsectores (Exploración, Producción y Refinación), el presente trabajo busca tener una visión, con énfasis en el punto de vista económico, de las variables que inciden en la situación actual de producción petrolera en Colombia, mediante el análisis de su planeamiento estratégico. La pregunta de investigación que se busca responder a través del siguiente trabajo es la siguiente: ¿Cuál es la situación estratégica de la producción petrolera en Colombia?, por lo que el objetivo central consiste en evaluar la situación estratégica de la producción petrolera en Colombia en el año 2013; para cumplir con ese objetivo, se evalúan los factores externos e internos de la producción colombiana de petróleo, se analizara la relación entre el producto interno bruto y las ventas de petróleo, así como la participación de los impuestos generados por la producción de petróleo en los ingresos generales del Estado en el año 2013 y la participación de las exportaciones petroleras en la balanza de pagos en el año 2013.

\subsection{Antecedentes de la industria petrolera}

Empresa Colombiana de Petróleos (conocida mundialmente como Ecopetrol) emprende labores en 1951, y desde entonces ha tenido el control total de este sector de hidrocarburos en Colombia. 
Colombia ha visto un aumento en la producción de petróleo del 2008 al 2012 luego de períodos en que el sector se vio abandonado, y estos aumentos en la producción se debieron a que el gobierno Colombiano promulgó una serie de reformas normativas para que el sector sea más atractivo para los inversores extranjeros. Además, puso en marcha una privatización parcial de la petrolera estatal Ecopetrol, en un intento de revivir su industria petrolera aguas arriba lo cual funciona. Otro parámetro que influye es la mejora en el orden público del país, esto asociado a la disminución de los atentados terroristas contra la infraestructura petrolera, lo cual genera confianza inversionista.

El sector petrolero de Colombia es el mayor contribuidor a la economía de Colombia. El vicepresidente del Instituto Nacional de Estadística (INE) Pedro Solbes afirmó que por medio de este solo sector, el PIB del país ha crecido en un promedio del 3\% cada año desde 1997. Durante este tiempo, Estados Unidos ha sido el mayor comprador del petróleo de Colombia, comprando casi dos terceras partes del todo el crudo de Colombia cada año.

La industria ha atraído la inversión extranjera incluyendo a Mobil, Esso, Texaco, Oxy, Shell, BP y otras, de las principales empresas multinacionales de energía que operan al amparo de asociación de los modos de concesión en el país. La industria en Colombia incluye empresas de producción, servicios petroleros, empresas de asesoramiento y apoyo a un sector manufacturero con equipos, instalaciones y materiales, esto se demuestra con las Cifras del Banco de la República que muestran que al diez de Enero de 2013, la Inversión Extranjera Directa (IED) en Colombia se aceleraba en un $48,71 \%$, proyectando un crecimiento de la IED en el sector petroquímico de un $0,86 \%$, aproximadamente unos US $\$ 16.822$ millones.

La mayor parte de la industria petrolera colombiana se ejecuta a través de empresas conjuntas entre Ecopetrol y las empresas extranjeras, algunas de las cuales han financiado en gran medida la construcción de las tuberías para transporte del petróleo, de 
igual modo la inversión de estas empresas multinacionales ha llevado a la creación de la infraestructura petrolera que existe hoy en Colombia. BP y Occidental Petroleum se encuentran entre las mayores empresas extranjeras en el sector petrolero colombiano. La gran parte de la producción de crudo de Colombia se produce en las cuencas de los valles Superior y Medio del Magdalena, Catatumbo, La Guajira, cordillera Oriental, Putumayo y Llanos Orientales. El campo más grande en el país es el de Cusiana / Cupiagua complejos operados por BP, la cual "acordó vender sus negocios de exploración, producción y transporte de petróleo y gas en Colombia a un consorcio formado por la compañía nacional petrolera colombiana Ecopetrol (en un 51\%) y por Talisman de Canadá (en un 49\%)", indica un comunicado de la firma en Agosto de 2010 (El Espectador, Economía. 3 de Agosto de 2010).

De acuerdo con Oil and Gas Journal (O \& GJ), en Colombia había 1.360 millones de barriles de reservas probadas de petróleo crudo en enero de 2010, posicionándose dentro de las cinco reservas más grandes en América del Sur, lo anterior fue el resultado de incentivos que permitieron el aumento de la producción de petróleo, la cual llegó a niveles de aproximadamente 680.000 barriles de petróleo por día (bbl / d) en 2009, un aumento de $600.000 \mathrm{bbl} /$ respecto al año inmediatamente anterior.

Con el consumo de petróleo en el país que llegó a un estimado de $282.000 \mathrm{bbl} / \mathrm{d}$ en 2010, el excedente de producción fue exportado a Estados Unidos desde Colombia, lo que permitió un desarrollo económico e incentivos al gasto público que afectaron positivamente el consumo la política económica y social de los colombianos.

Primero es importante conocer la producción petrolera en Colombia. En el país la producción de petróleo tiene como objetivo satisfacer las necesidades propias y el excedente de la producción, constituye las exportaciones (Banco de la República de Colombia, 2013). Según Ricardo Perilla (2009), el total de la producción se distribuye en $46 \%$ para consumo interno, como productos del proceso del petróleo en refinerías; y el restante 54\% para exportación. La mayor parte del procesamiento del petróleo, se realiza 
en las refinerías de Barrancabermeja y Cartagena (Banco de la República de Colombia, 2013). La gasolina y el diésel, producto de las refinerías, cubren (en su mayoría) la demanda del sector transporte y las demandas de otros sectores como servicios, primario y exportaciones que son menores al 25\% (Perilla, 2009). Además se debe tener en cuenta que Colombia, no es un país de gran producción petrolera. Que como indica el Banco de la República de Colombia (2012), está directamente relacionado con las "reservas petroleras relativamente pequeñas" del país.

En la producción petrolera participan dos tipos principales de firmas. El primero lo componen las empresas con capital privado, que en general son filiales de una casa matriz extranjera, y que actualmente tienen una participación del 32\% en la producción nacional de hidrocarburos. La estatal petrolera (Ecopetrol), es la otra firma que participa de este negocio, y es el principal referente para la industria con un aporte a la extracción de crudo en el país equivalente al $68 \%$ del total nacional. El incremento de la participación de Ecopetrol, obedece en su mayoría a la terminación de contratos de asociación que pasaron en su totalidad a la empresa, a la adquisición parcial o total de empresas privadas (Hocol y Equion), y al uso de nuevas tecnologías para incrementar el factor de recobro de los campos (Banco de la República de Colombia, 2013).

Lo anterior permite inferir que dentro la desregulación y desarrollo del mercado de derivados de petróleo, la entrada de nuevos actores privados que permitan luego de las estepas de producción, incrementar los desarrollos y avances en la refinación del petróleo crudo para fortalecer el desarrollo económico del país, es requerida la adopción de medidas previas, necesarias para crear condiciones que faciliten su acceso, esto por medio de garantías que permitan de manera efectiva que el sistema de transporte sea neutral, abierto y con una operación descentralizada, facilitar la importación privada e independiente de combustibles y el acceso al mercado mayorista de nuevos comercializadores, en igualdad de condiciones con los actuales operadores. 


\section{FACTORES EXTERNOS QUE INTERVIENEN EN LA PRODUCCIÓN PETROLERA EN COLOMBIA}

Es importante conocer las relaciones del sector petrolero con la economía nacional, como se muestra en la Figura 2-1, dado que esa visión permite identificar qué sectores se ven afectados, si se afecta el sector petrolero, así como en algunos casos, cuáles sectores pueden llegar a afectar al sector (Banco de la República de Colombia, 2013). Al ser una de las fuentes de energía más importante, tanto el petróleo sus derivados; "se utiliza directa e/o indirectamente, en las distintas actividades económicas" (Naciones Unidas CEPAL, 2013). Al igual que los cambios en la producción petrolera y en los precios internacionales, alteran las exportaciones nacionales impactando el Producto Interno Bruto (en adelante PIB) (Banco de la República de Colombia, 2013).

Figura 2-1: Vínculos del sector petrolero con la economía nacional

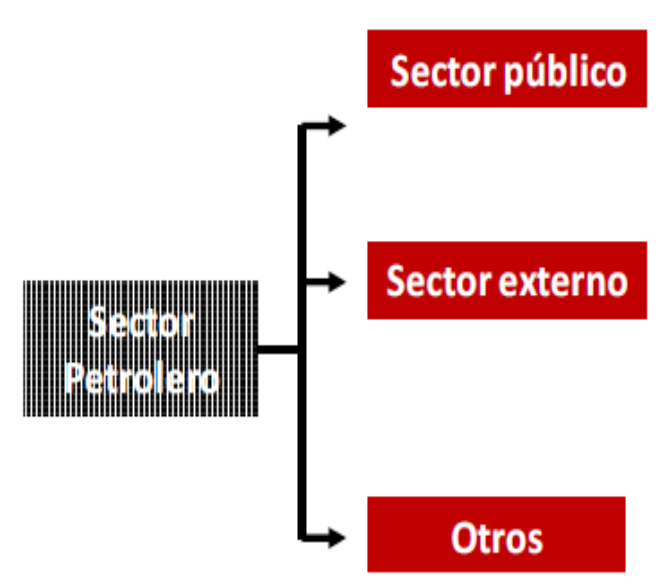

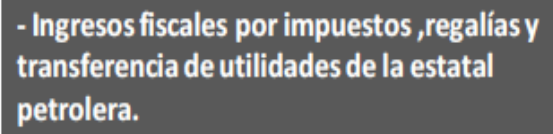

- Encadenamientos productivos con otros sectores por demanda y oferta de insumos. -Demanda de mano de obra.

- Inflación debido a cambios en los precios del crudo.

Fuente: Banco de la República de Colombia (2013) 
De acuerdo con la Figura 2-1, el petróleo incide en el sector público, en el sector externo y en otros sectores; a nivel externo su relación se explica por los importantes montos de inversión extranjera directa que puede generar, su importancia en las cifras de comercio exterior, la salida de dólares cuando se realiza el pago de utilidades a las casas marices de las empresas que operan en el país, los términos de intercambio tecnológico y económico que la industria plantea y los efectos que producen esas operaciones en la variación de la tasa de cambio.

También es interesante resaltar que el aumento en la producción de petróleo, es necesaria para el crecimiento de los demás sectores económicos, que tienen como insumo importante este combustible, haciendo clara la dependencia de esos sectores en el sector petrolero (Banco de la República de Colombia, 2013).

\subsection{Situación geopolítica.}

Según Perilla (2009) un factor importante que interviene en la producción y precio del petróleo es la "tensión política que se vive en países productores", puesto que genera incertidumbre respecto al suministro del petróleo, fenómeno que se relaciona con los eventos de violencia presentados en el segundo bimestre de 2004 que en la comunidad internacional generaron duda acerca de "la capacidad de Irak para convertirse en un productor estable y seguro" (Perilla, 2009). Otros de los países productores de petróleo que afectan el mercado, debido a sus conflictos políticos, son Irán, Nigeria y Venezuela (Ramírez \& Cuéllar, 2013).

Al igual que Perilla (2009), el Banco de la República (2012), señala que la producción colombiana de petróleo se relaciona de forma cercana con el entorno político del país. Sánchez (2010), por su parte, indica que los factores políticos tienen un impacto mucho mayor en los países productores de petróleo, que pertenecen a la Organización de Países Exportadores de Petróleo (en adelante OPEP), mientras que en los países no 
pertenecientes a esta organización, un factor que genera mayor impacto es el económico, como consecuencia de la variabilidad en el precio internacional del petróleo (Sánchez, 2010).

Otro factor político importante que afecta la producción petrolera nacional son las políticas contractuales establecidas por el Estado para el explotación de ese recurso natural (Banco de la República de Colombia, 2013). La importancia de este factor se evidenció con los efectos que tuvo la creación de la Agencia Nacional de Hidrocarburos (ANH) como organismo independiente de Ecopetrol, donde la ANH a partir del año 2003 con el decreto 1760, para cumplir el objetivo de diseñar, negociar y establecer las condiciones de los contratos de exploración y explotación de petróleo en el país, así como coordinar la liquidación de regalías luego de analizar el potencial hidrocarburífero Colombiano en sus diferentes áreas geográficas, dado transparencia, independencia y autonomía a través de unas reglas claras al sector de empresas interesadas en el negocio y así Ecopetrol se dedicó a explorar, producir, transportar, refinar y comercializar hidrocarburos, compitiendo en las mismas condiciones con las demás empresas petroleras del mercado Colombiano.

\subsection{Demanda externa de petróleo.}

La demanda energética mundial ha aumentado en los últimos años y ha sido cubierta por distintos tipos de combustibles entre ellos el carbón y el petróleo (Ramírez \& Cuéllar, 2013). Este aumento está relacionado con el crecimiento de las industrias de países como China e India (Naciones Unidas CEPAL, 2013). También es importante tener en cuenta que el consumo de petróleo por parte de los distintos países, se ve afectado por su propio crecimiento económico tal como se demuestra en el período entre 2004-2007, cuando los países desarrollados presentaron un menor crecimiento económico, generando aumentos menores e incluso detrimentos en el consumo de petróleo, a los presentados en periodos anteriores (Naciones Unidas CEPAL, 2013). Impacto importante pues estos países consumen el $80 \%$ de la producción petrolera mundial (Naciones Unidas CEPAL, 2013). 
El Banco de la República (2012) señala que los cambios en la demanda internacional de petróleo afectan el nivel de la producción del mismo en Colombia, de manera que al aumentar la demanda internacional, la producción y su flexibilidad tecnológica "responde significativamente" al choque de demanda internacional teniendo claro que y al disminuir este efecto no se reducen los incentivos para disminuir la producción de petróleo Colombiana.

Así pues usando lo planteado por Nicholas Murray Butler Miembro del Council on Foreign Relations, en cómo se desarrollan los hechos mundiales, clasificando en tres grupos a quienes lo componen, siendo un pequeño número de muy importantes personas quienes en verdad hacen producir los acontecimientos; un grupo un poco menos importante quienes vigilan la ejecución de tales acontecimientos haciendo que se cumplan y al final una vasta masa que jamás sabrá lo que en realidad ha acontecido.

El petróleo no se sale de los parámetros anteriormente expuestos, ya que es precisamente un tema cuyo análisis no despierta la pasión de multitudes y generalmente se cree que para entenderlo se debe ser un especialista con vastos conocimientos técnicos, además de notables aristas económicas, debido a estas razones la estrategia del uso del petróleo se basa en que debe tomarse en cuenta que la vida de todos los individuos puede ser analizada desde un punto de vista de transformación de la energía (vestimentas, pensamientos, o desarrollo de cualquier actividad diaria) ya que no se realiza otra cosa que procesar energía.

Por lo tanto desde el consumo de cualquier alimento que refleja su valor monetario en lo sembrado, más el trabajo utilizado en todas las etapas de producción, más la gasolina que se usó para la maquinaria de cultivar los campos, más el petróleo que se empleó para trasladar la siembra a la industria molinera, más el combustible utilizado para transformar las materias primas que terminan siendo el alimento, más la cantidad de energía mayoritariamente concentrada en hidrocarburos destinada a los procesos de empaque, mercadeo y distribución, están relacionados al componente energético en 
forma de hidrocarburos, el cual es un factor muy relevante dentro del costo total del producto.

Por ende si a su vez tenemos en cuenta que los salarios abonados por el trabajo se gastan también en consumo de energía, debemos inferir que la energía mueve al mundo y que la disminución de la demanda de Petróleo, no incentiva una disminución de producción necesariamente, dado que los niveles de bienestar tan exigentes en la sociedad actual dependen en gran medida de los sistemas de precios y salarios regulados por el mercado, girando en torno a la escases o abundancia de la energía que interviene en los procesos productivos.

\subsection{Precio internacional del petróleo.}

Los actores principales que intervienen en el mercado de petróleo son las empresas públicas de los países productores de petróleo ${ }^{1}$, empresas europeas relacionadas con los países latinoamericanos ${ }^{2}$, así como empresas de los Estados Unidos ${ }^{3}$ y también se encuentra a partir de los años setenta la Organización de Países Exportadores de Petróleo (OPEP). Además en el mercado del petróleo son muy importantes "los pronunciamientos de la Agencia Internacional de la Energía" así como los del departamento de energía de los Estados Unidos de América (EE.UU.) (SánchezAlbavera \& Vargas, 2005). La interacción de los actores la cual consiste en que en mantener los precios estables y libres de toda fluctuación innecesaria, teniendo claro que si surge alguna nueva circunstancia que requiera modificación de precios, se definirá un

\footnotetext{
${ }^{1}$ Las empresas públicas son: Saudi-Aramco de Arabia Saudita, NIOC de Irán, KPC de Kuwait, ADNOC de los Emiratos Árabes Unidos, NOC de Libia, NNPC de Nigeria, PDVSA de Venezuela, Pemex de México y Petrobras de Brasil (Sánchez-Albavera \& Vargas, 2005).

${ }^{2}$ British Petroleum, Shell, Total, REPSOL.

${ }^{3}$ MOBIL OIL, EXXON, Texaco y Amoco.
} 
sistema para asegurar la estabilización de los mismos regulando la producción con la debida atención hacía los intereses de las naciones productoras y de las consumidoras, así como la necesidad de garantizar unos ingresos estables a los países productores, un abastecimiento eficiente, económico y regular de esta fuente de energía a las naciones consumidoras, y una justa ganancia para su capital a quienes inviertan en la industria del petróleo, así como de las entidades cuya opinión afecta directa o indirectamente el sector; son los principales reguladores del precio internacional del petróleo.

En cuanto a la OPEP, es una organización que inciden en el precio del petróleo, tomando como referencia la demanda del mismo, así como la demanda de gasolina y la situación económica de los EE. UU (Organización de Países Exportadores de Petroleo, 2014). E precio internacional del petróleo impacta de manera importante las demás industrias, pues este combustible sigue siendo la principal fuente de energía a nivel mundial, por lo que la industria petrolera logra generar un gran impacto en la economía mundial.

Al igual que todos los productos, el precio del petróleo se ve afectado por la interacción de la oferta y la demanda (Naciones Unidas CEPAL, 2013). Ricardo Perilla (2009) y Sánchez (2010), describen que otro de los factores que afecta la producción de petróleo es el precio internacional del mismo, el que de 2002 a 2008 tuvo un aumento anual promedio del 25\% (Naciones Unidas CEPAL, 2013). El efecto es constatado en la historia de producción de petróleo en el país, donde se presentaron reducciones importantes, en periodos de altos precios internacionales y ascensos relevantes en la producción en periodos de precios internacionales bajos (Sánchez, 2010). Aunque en contraste con estos autores, el Banco de la República (2012), indica que en Colombia no se presenta una respuesta inmediata por parte de la producción petrolera ante los cambios en el precio internacional, posiblemente debido a "limitaciones de la capacidad instalada", que impiden una adaptabilidad de la producción nacional. Sin embargo, los precios internacionales de petróleo, pueden afectar la producción en el futuro, debido a que un alza en los precios puede incentivar la inversión en el sector, aumentando la producción (Banco de la República de Colombia, 2012). 
La evolución de los precios del petróleo West Texas Intermediate (en adelante WTI, usado como referente internacional), se muestran en las Figura 2-2 y

Figura 2-3. En la Figura 2-2 se muestra que el precio del petróleo WTI presentó un ciclo de descenso entre 1980 y 1998, seguido de un rápido crecimiento entre 1999 y 2007.

Es importante tener en cuenta el manejo estratégico de la oferta de petróleo por parte de los países de la OPEP, sumado con la especulación económica, generan cambios importantes en el precio internacional del petróleo, lo que a su vez genera los cambios en la producción petrolera de países no pertenecientes a la OPEP como Colombia, mencionados anteriormente (Sánchez, 2010).

Figura 2-2: Precios promedio anuales del petróleo WTI (1999-2013)

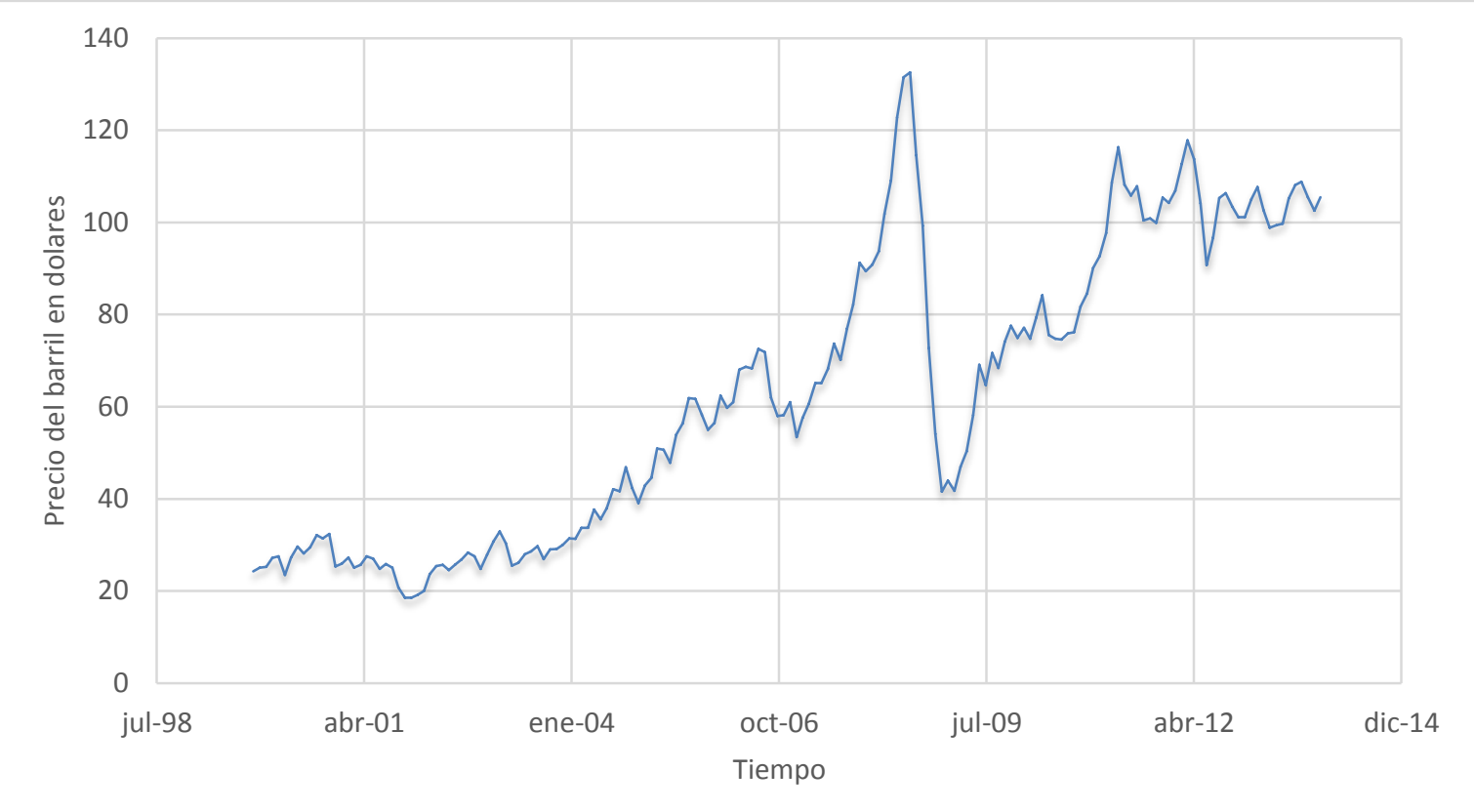

Fuente: Naciones Unidas, Comisión Económica Para América Latina y el Caribe (2013)

Según Sánchez-Albavera y Vargas (2005), el petróleo por ser un "producto básico que se transa en mercados de futuro" es susceptible de movimientos financieros estratégicos que permitan ganar o mantener el valor, por lo que su precio puede ser alterado por la especulación "provocada explícitamente o derivada de acontecimientos inesperados o de 
situaciones de conflicto latente que al incubarse provocan nerviosismo en los agentes que operan en los mercados bursátiles". (Sánchez-Albavera \& Vargas, 2005, pág. 17)

Figura 2-3 en la que se muestra la evolución diaria del precio del petróleo WTI entre 2008 y 2014; esa evolución fue de descenso hasta 2009 y de lento pero constante incremento hasta 2014, alcanzando un precio cercano al doble del que existía en 2009.

Actualmente el precio del petróleo se encuentra alto, debido principalmente al aumento de la demanda y a "debilidades en la producción global" (Ramírez \& Cuéllar, Clúster del petróleo y el gas evaluación del entorno competitivo, agenda estratégica y elementos de una iniciativa de desarrollo del clúster, 2013). Esto ha generado dos respuestas, primero la inversión de capital en formas de producción de petróleo, que anteriormente no eran rentables con precios bajos. Los altos precios también han estimulado el uso de combustibles alternativos (2013) y la investigación en el desarrollo de nuevas tecnologías de explotación y de nuevas fuentes de energía. 
Figura 2-3. Precio Diario del Petróleo WTI (2008-2014)

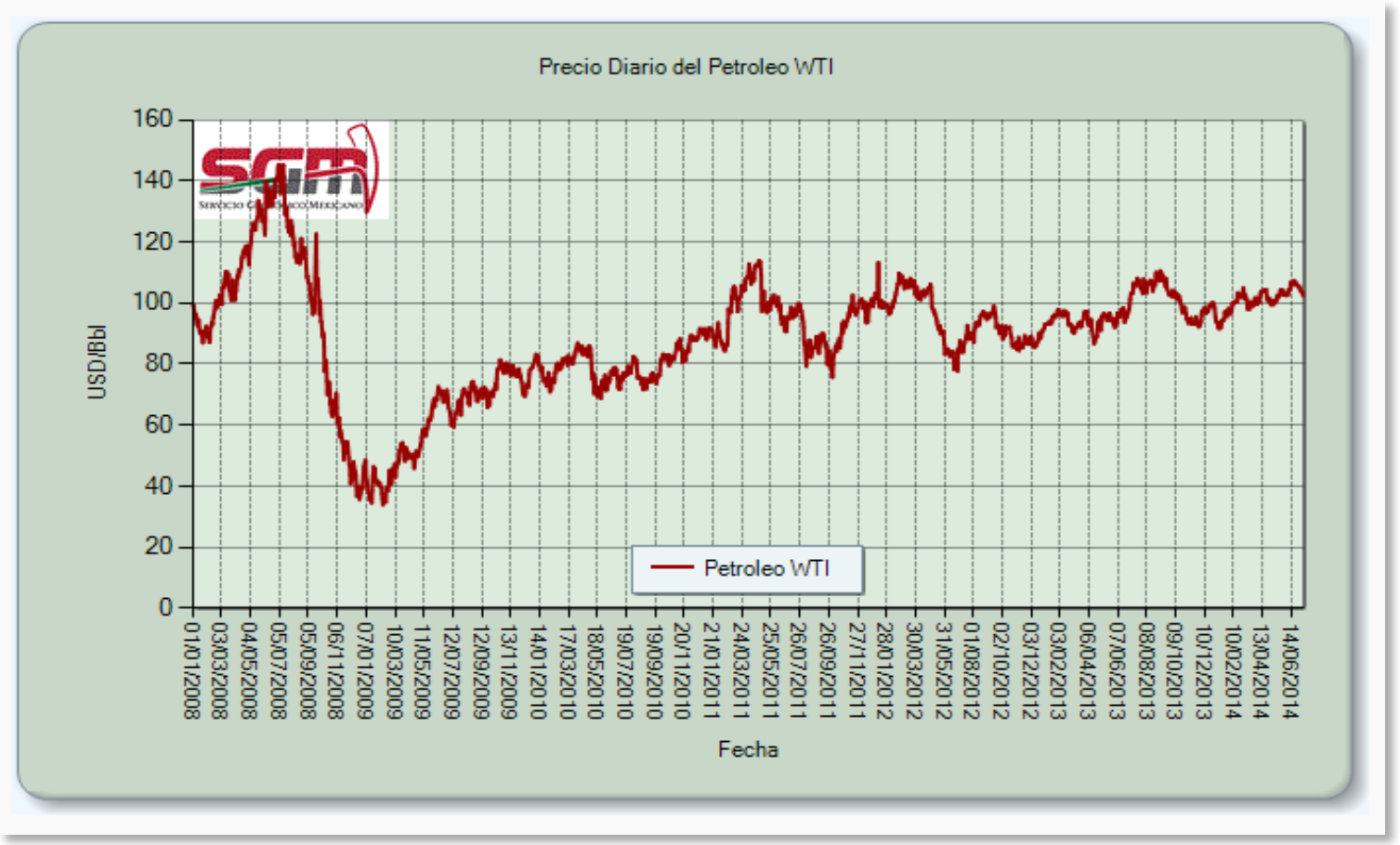

Fuente: Servicio Geológico Mexicano (2014)

Los precios favorables que se presentan actualmente en el mercado del petróleo, estimulan a las compañías a invertir en la búsqueda de nuevos yacimientos y a optimizar las actividades que realizan actualmente. Alrededor del mundo la inversión en tecnología, para el sector petrolero busca:

- $\quad$ Ampliar los futuros suministros de hidrocarburos convencionales

- $\quad$ Producir en forma rentable fuentes no-convencionales de hidrocarburos

- Mejorar los porcentajes de recobro primario y secundario

- Reducir los costos de exploración, producción y desarrollo, mediante tecnología más eficiente

- Disminuir fuertemente los daños ambientales causados por las actividades del sector, mejorando la imagen del sector (Ramírez \& Cuéllar, 2013). 
En la década de los noventa, los precios elevados así como cambios en la regulación, incrementaron la Inversión Extranjera Directa (en adelante IED). Este capital se invirtió en actividades exploratorias, por lo que se aumentó la actividad sísmica y se perforaron pozos exploratorios, así como también, se invirtió en desarrollo e implementación de nuevas tecnologías para la extracción de petróleo (Banco de la República de Colombia, 2013). Estas inversiones han permitido el incremento de la producción petrolera del país, que se muestra en la Figura 2-4.

Figura 2-4. Producción de Petróleo de 2009 a 2013 en Colombia

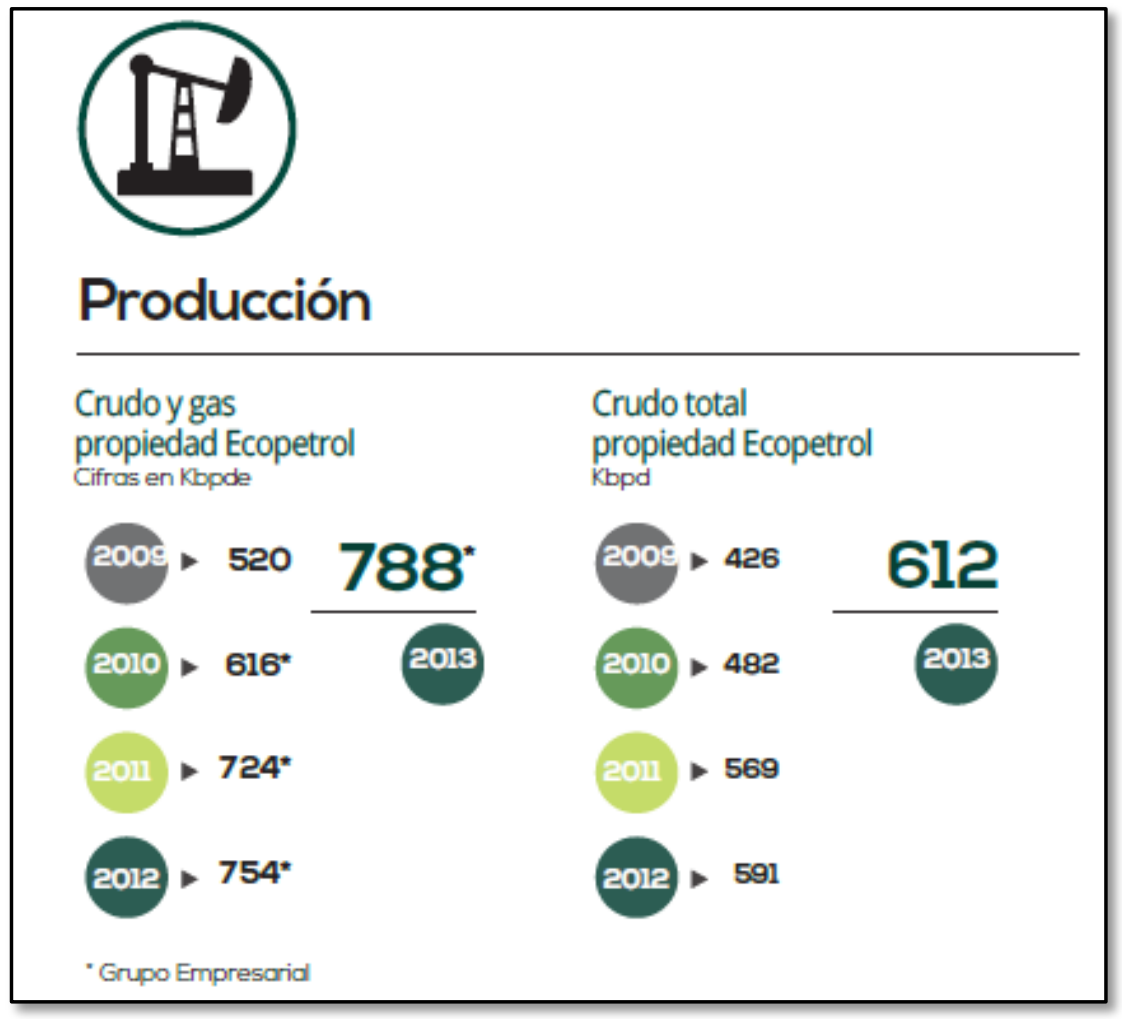

Fuente: Ecopetrol (2014)

Según Ramírez y Cuéllar (2013), este crecimiento del sector petrolero, ha generado una escasez de mano de obra calificada, maquinaria y servicios especializados aumentando los costos de producción. 


\subsection{Factores propios de la industria petrolera.}

Ya que el petróleo es un recurso natural no renovable, su producción depende de las reservas descubiertas, así como de la capacidad de extracción de cada uno de los países, lo que necesariamente va disminuyendo de manera progresiva las reservas de los países productores (Ramírez \& Cuéllar, 2013). Arabia Saudita, Irán, Kuwait, Emiratos Árabes Unidos, Libia, Nigeria, Venezuela y México, son los países que tienen el $80 \%$ de las reservas petroleras a nivel mundial (Sánchez-Albavera \& Vargas, 2005).

Es importante destacar que las reservas petroleras a nivel mundial siguen siendo altas y se mantienen en aumento, aunque la producción de petróleo al nivel mundial, no ha aumentado de la misma manera, manteniéndose cerca de los 81,5 millones de barriles diarios (Ramírez \& Cuéllar, 2013), lo que hace que la fase exploratoria se vuelva muy importante, pues es la que permite sustituir los pozos que se van agotando (Unidad de Planeación Minero Energética, 2005).

La exploración de viejos campos petroleros y el alza mundial del precio del petróleo explican el aumento de la producción del crudo en Colombia a partir del 2008, lo cual no significa que el país esté en bonanza, entre el 2009 y 2010 la producción petrolera colombiana y su flexibilidad tecnológica para la producción de petróleo se incrementó. La agencia EFE indicó que en el 2009, el nivel de producción de petróleo colombiano llegó a niveles de 670.000 barriles diarios. Si se compara con la de 618.000 del 2008, el incremento es del $8 \%$ y, comparada con la del 2007 , el aumento es del $17 \%$.

Es claro que Colombia no es un país petrolero, se han descubierto reservas, sin embargo frente al total mundial, apenas llega a una décima del 1\% del total, se puede manifestar que el aumento de la producción colombiana de los últimos años se explica fundamentalmente por el aumento mundial del precio del crudo dado que es un incentivo monetario que motiva al aumento del nivel de producción, con base en choques de demanda. 
La caída de precios en el periodo crítico para la economía mundial del año 2009 fue pasajera y las estimaciones de precios para años siguientes se ponderaban entre el rango de 70 y 80 dólares, por lo cual la rentabilidad de petróleos de altos costos de extracción y de baja calidad se mantiene.

Esta situación ha hecho rentable la producción de viejos campos de crudos pesados y extra-pesados descubiertos hace muchos años en Colombia: Castilla en 1969, Apiay en 1981, Rubiales hacia el 2000. El alto precio ha permitido una campaña de inversiones complementarias sobre los campos descubiertos, que ha llevado a una mejor valoración de las reservas, en el año 2005 los crudos extra-pesados se producían y transportaban de manera ineficiente con ayuda de camiones, así pues la gran inversión en transporte en el departamento del Meta permite incluso explotar campos con pocas reservas. Los esfuerzos exploratorios en áreas realmente nuevas son más bien precarios y es por eso que el mapa de reservas del país se mueve poco, excepción hecha de las reevaluaciones de los viejos campos.

Otro de los factores señalados es que al presentarse una aceleración del crecimiento económico de los países productores, se ve positivamente estimulada la producción petrolera; aunque si en los países como Colombia se presentan desaceleraciones en el crecimiento económico en otros sectores industriales, no se ve directamente relacionada a una disminución en la producción de petróleo, esto debido a que ya se han realizado las inversiones correspondientes que obligan a mantener el ritmo de la producción para recuperar dichas inversiones. Todos estos factores que afectan la producción de petróleo, deben evaluarse teniendo en cuenta circunstancias como el impacto generado por fenómenos como el colapso financiero mundial de 2008 (Naciones Unidas CEPAL, 2013).

A su vez, los países petroleros se están incentivando a promover el control de sus reservas petroleras, aplicando normas de operación y regulación para la participación de empresas privadas, sin por ello dejar el control de las reservas en otras manos ni dejar la industria de petrolíferos en manos externas. 
Mundialmente la dependencia de los países al petróleo como fuente de generación de energía se mantendrá en los próximos años; se estima que todavía en los próximos 50 años el mundo tendrá una dependencia de las energías fósiles de un 50\% adicional al consumo actual. Algunas tendencias del mercado petrolero se enuncian a continuación:

a) La industria petrolera ha asimilado los cambios producidos por la globalización, lo que ha originado cambios en su política y en su gestión de negocios. El negocio se ha diversificado y hoy la actividad petrolera no se encuentra concentrada en pocos grupos, sino que se ha diversificado.

b) El mercado petrolero es un mercado signado por la incertidumbre, en el que confluyen diversos factores -económicos, técnicos y políticos- y en la determinación del precio privan las relaciones entre los agentes del mercado OPEP, NO-OPEP, compañías y consumidores.

c) La demanda petrolera no detendrá su crecimiento y dependerá principalmente de la recuperación económica especialmente del desarrollo de las economías emergentes que requerirán de más energía. La demanda petrolera tenderá a concentrarse en el consumo de gasolina y seguirán aumentando las restricciones ambientales al consumo.

d) Los análisis sobre las reservas y los costos indican que no existe previsión de agotamiento petrolero en el corto plazo, que no se anticipa ninguna penuria petrolera y que los precios presionados por estos dos factores, abundancia de reservas y bajos costos de explotación, propician el descenso, la estabilización o la baja. Sin embargo los fenómenos especulativos y las estrategias de frenado a los procesos de explotación, actúan en dirección contraria.

e) La OPEP irá recuperando una mayor cuota de participación en el total petrolero con base a sus abundantes reservas y los bajos precios, mientras que los países 
No-OPEP de bajas reservas y con necesidad de nuevas inversiones no son atractivos para inversiones, en especial si se producen procesos de apertura en los países del golfo.

Al aplicar la metodología de Porter (1991) La cual se basa en el análisis estratégico y sus parámetros y en el modelo de las cinco fuerzas competitivas para el análisis de los sectores, la cadena de valor y la clasificación de las estrategias, donde en el caso de la cadena de valor ésta se concibe como una función que supone la puesta en marcha de un conjunto de competencias económicas, de gestión y psicológicas; para el caso de la industria del petróleo el escenario en el que corresponde aplicar dicha metodología es el mercado global, dado que se trata de una industria de exportación y no de consumo interno del país en donde se realice la producción. Se trata de un mercado de vendedores, pues son ellos los que ejercen el poder de negociación, en el que la entrada de nuevos participantes se encuentra restringida por la exigencia de altos niveles de inversión y de conocimiento de la tecnología de la industria; adicionalmente, la sustitución de los productos derivados del petróleo no representa aún una amenaza importante aunque la tendencia es creciente como consecuencia de la tendencia mundial a evitar la contaminación ambiental. En cuanto a la rivalidad entre competidores, en el caso colombiano ésta se encuentra regulada por los mecanismos de contratación de la ANH y del Estado en general. Estas circunstancias hacen que la competitividad en la industria del petróleo se dé por dos razones principalmente: por la presencia de yacimientos y por la existencias de condiciones económicas, sociales y políticas atractivas para la inversión extranjera; en el caso de Colombia las circunstancias anteriormente mencionadas se cumplen, lo que permite concluir que en el país existen razones sólidas para esperar un importante crecimiento de la producción de petróleo en los próximos años, como los pronósticos para el petróleo Brent indican que estará en el 2014 en promedio a 105 dólares el barril, mientras que el WTI se podría mover entre 95 y 100 dólares.

De mantenerse el petróleo en estos niveles, es muy probable que los flujos de inversión extranjera sigan llegando a este sector, de todos modos se debe tener en cuenta que el precio del petróleo siempre será un alto riesgo para las finanzas públicas del país, lo que 
permite inferir que sea necesario hacer una reforma tributaria que aumente recaudo como base del gasto público.

\subsection{Matriz de evaluación de factores externos - MEFE}

A continuación se expresa un análisis al entorno nacional e internacional para identificar las oportunidades y amenazas para el sector petrolero de Colombia, las cuales se pueden observar en la Tabla 2-1.

Tabla 2-1. Matriz de Evaluación de Factores Externos del Sector Petrolero de Colombia 2013

\begin{tabular}{|c|c|c|c|}
\hline Factores & Peso & Valor & Pond. \\
\hline \multicolumn{4}{|l|}{ Oportunidades } \\
\hline 1. Incremento de la actividad petrolera & 0.1 & 3 & 0.3 \\
\hline $\begin{array}{l}\text { 2. Barreras para la producción de energías alternativas a gran } \\
\text { escala }\end{array}$ & 0.05 & 3 & 0.15 \\
\hline $\begin{array}{l}\text { 3. Dependencia del petróleo para la fabricación de gran } \\
\text { cantidad de productos }\end{array}$ & 0.05 & 3 & 0.15 \\
\hline $\begin{array}{l}\text { 4. Exenciones arancelarias para las importaciones temporales } \\
\text { de equipos petroleros }\end{array}$ & 0.1 & 4 & 0.4 \\
\hline $\begin{array}{l}\text { 5. Incentivos del Gobierno a la inversión extranjera y } \\
\text { generación de empleos }\end{array}$ & 0.1 & 3 & 0.3 \\
\hline $\begin{array}{l}\text { 6. Relación bilateral fuerte con Estados Unidos y otros } \\
\text { potenciales compradores. }\end{array}$ & 0.1 & 3 & 0.3 \\
\hline 7. Inmigración de personal calificado de países vecinos. & 0.05 & 3 & 0.15 \\
\hline 8. Incremento del precio internacional del petróleo. & 0.05 & 4 & 0.2 \\
\hline & 0.6 & & 1.95 \\
\hline \multicolumn{4}{|l|}{ Amenazas } \\
\hline 1. Condiciones geográficas desfavorables & 0.05 & 2 & 0.1 \\
\hline 2. Condiciones climáticas desfavorables & 0.05 & 2 & 0.1 \\
\hline $\begin{array}{l}\text { 3. Problemas sociales y de orden civil frecuentes que frenan } \\
\text { la inversión extranjera }\end{array}$ & 0.1 & 3 & 0.3 \\
\hline $\begin{array}{l}\text { 4. Sistema de transporte de crudo con baja conectividad } \\
\text { internacional }\end{array}$ & 0.1 & 3 & 0.3 \\
\hline \multirow[t]{2}{*}{ 5. Reservas de petróleo por debajo de lo esperado } & 0.1 & 2 & 0.2 \\
\hline & 0.4 & & 1.0 \\
\hline Total & 1.0 & & 2.95 \\
\hline
\end{tabular}

Fuente: elaboración propia. 
El objetivo de esta matriz es permitir la evaluación de características económicas, sociales, culturales, demográficas, ambientales, políticas, gubernamentales, jurídicas, tecnológicas y competitivas, según la estrategia a valorar, la matriz de Evaluación de Factores Externo para el sector petrolero en Colombia cuenta con 13 factores, 8 oportunidades y 5 amenazas. Se encuentran más oportunidades que amenazas lo cual le da al sector petrolero más posibilidades de éxito frente a otras industrias altamente competitivas. Por otro lado, se deben continuar los planes de choque para combatir las amenazas que enfrenta el sector como las escasas reservas de petróleo en comparación con países como Ecuador y las condiciones geográficas y climáticas que no favorecen las operaciones de exploración y explotación de hidrocarburos en el país.

\section{FACTORES INTERNOS QUE INTERVIENEN EN LA PRODUCCIÓN PETROLERA EN COLOMBIA}

Un diagrama de los factores internos que intervienen en la producción petrolera en Colombia, se presenta en la Figura 3-1. 
Figura 3-1. Determinantes de la producción de Hidrocarburos en el país.

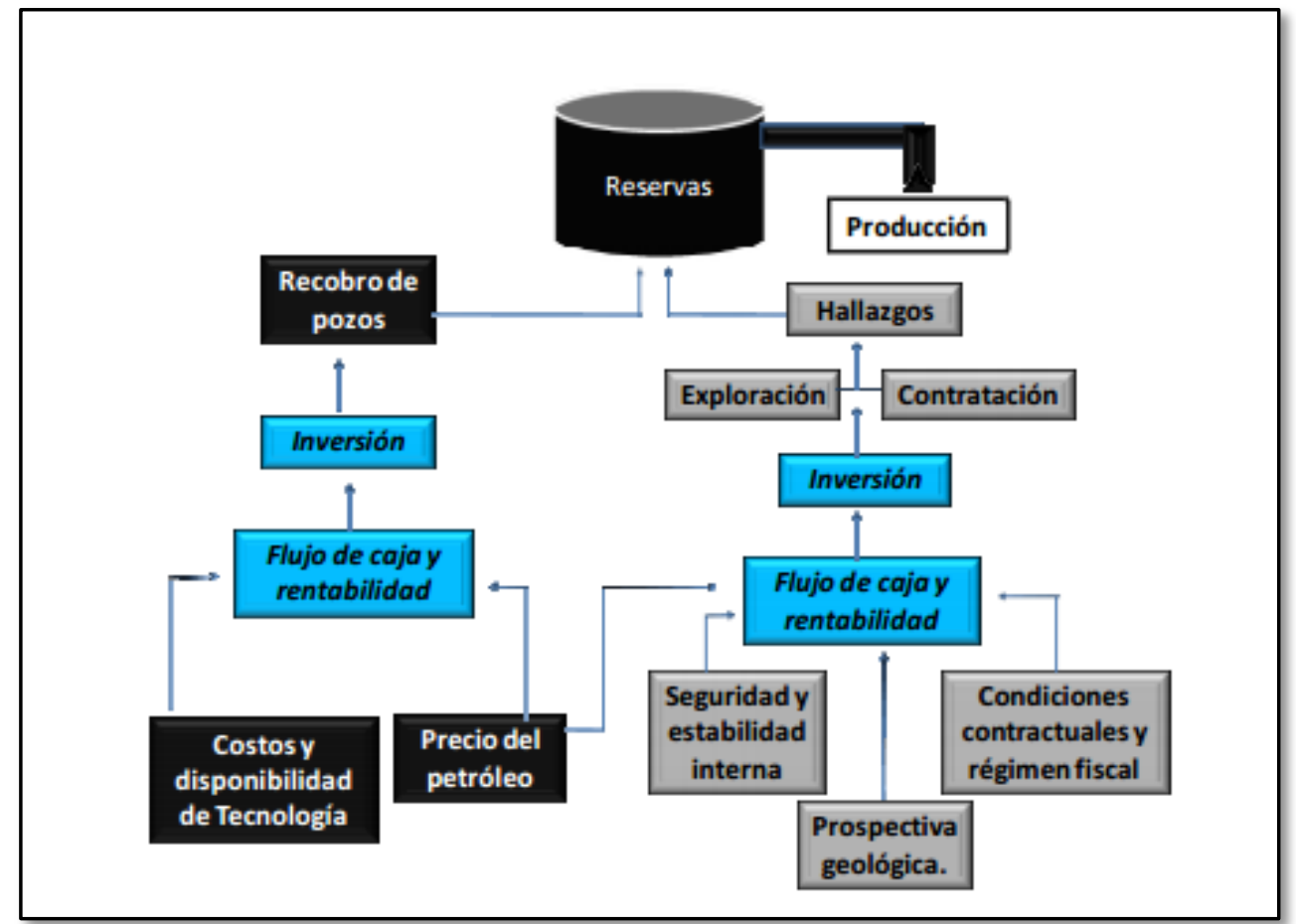

Fuente: Banco de la República de Colombia (2012)

El diagrama anterior expresa que la producción está relacionada con las reservas comerciales disponibles para explotar, las cuales se alimentan de los nuevos yacimientos $y$ de las variaciones en el factor de recobro de los campos, teniendo en cuenta que la probabilidad de descubrir nuevos depósitos de crudo y el aumento del recobro que permitan un incremento de las reservas, está antecedida y depende de los niveles de inversión de riesgo en exploración, uso de tecnologías de extracción y desarrollo de los campos. La inversión destinada a estas actividades depende de la rentabilidad para el inversionista, la cual varía de acuerdo factores que afectan los ingresos y costos de las compañías. 
Las reservas de petróleo se incrementan en la medida en que se incrementan los hallazgos y se aplican tecnologías que permiten la recuperación de pozos que habían llegado a sus máximos niveles de explotación cuando se manejaron con tecnologías menos desarrolladas. A su vez, los hallazgos se ven favorecidos por la inversión, ya sea que la misma provenga de utilidades de los actuales operadores, o por inversión extranjera directa. Las condiciones básicas necesarias para que todos estos procesos se produzcan, son la seguridad y la estabilidad política interna, así como las condiciones contractuales y un régimen fiscal que resulte suficientemente atractivo tanto para los inversionistas extranjeros, como para el Estado. La actividad de geología es a su vez la que va permitiendo identificar las regiones del país en donde se pueden celebrar contratos con las compañías que realizan esta actividad.

El recobro de pozos, por su parte, depende también de inversiones que se dan en la medida en que el flujo de caja y la rentabilidad lo permitan. El precio internacional del petróleo, así como los costos y la disponibilidad de la tecnología necesaria, son los que determinan la conveniencia de hacer las inversiones, dado que normalmente se trata de tecnologías más costosas que las convencionales, por lo que sólo se aplican en momentos en que el precio internacional es alto, sin embargo el propósito de los mercados estratégicos como lo es el petrolero es la flexibilidad tecnológica, la cual hace parte de las restricciones que están asociadas a la optimización de los costos y la incorporación de variables de insumo $(x)$ producto $(y)$ como un conjunto de planes o posibilidades de producción factibles $(\vec{Y})$, como un sistema de requisitos de insumos $\overrightarrow{V_{y}}=\left\{x\right.$ en $\left.R^{n} \mid((y,-x) \in \vec{Y})\right\}$, como una equivalencia de cantidades $Q(y)=\left\{x \in R^{n} \mid x \in \overrightarrow{V_{y}}, x \nexists \overrightarrow{V_{y^{\prime}}}\right.$ para $\left.y^{\prime}>y\right\}$, como una función de transformación $\mathrm{T}(\mathrm{y})=0$ 。 en el caso del nivel de producción de petróleo una función de producción

$$
y=f(x)=\left\{\begin{array}{c}
y, \text { es el maximo producto con factores de insumos } x \\
y, \text { es el único producto a generar (Petróleo })
\end{array}\right.
$$

Donde $y=f(x)=\{y \in R \mid y$ es el max producto asociado $a-x$ en $\vec{Y}\}$ 


\subsection{Situación geopolítica y legislativa.}

En 1948 se crea Ecopetrol, la empresa del gobierno encargada de recibir la concesión de Mares, dando inicio a la intervención del Estado en la cadena productiva del petróleo; antes de eso, el sector petrolero nacional, era manejado por empresas extranjeras (Banco de la República de Colombia, 2012). A partir de este momento inician una serie de cambios en cuanto a legislación y a aspectos empresariales. Los cambios relevantes se resumen a continuación:

- $\quad$ Ley 20 de 1969, en la que se "establece el principio de propiedad absoluta de la Nación sobre las minas y yacimientos de hidrocarburos, respetando los derechos preestablecidos en favor de terceros particulares con algunas condiciones para su ejercicio".

- $\quad$ Ley 28 de 1974 (Decreto Legislativo 2310), en el "cual abolió hacia el futuro el régimen de la concesión petrolera e impuso otros tipos de contratos para la exploración y explotación de los hidrocarburos de propiedad nacional, como el de asociación". Además de forma exclusiva se le delegan a Ecopetrol las funciones de exploración y explotación, las que podrían ser desarrolladas directamente o las contrataba con personas naturales o jurídicas, nacionales o extranjeras (Banco de la República de Colombia, 2012).

- Constitución de 1991. Mediante el Artículo 332 establece que "El Estado es propietario del subsuelo y de los recursos naturales no renovables, sin perjuicios de los derechos adquiridos y perfeccionados con arreglo a las leyes preexistentes" (Asamblea Nacional Constituyente, 1991). Según el Banco de la República (2012), también se remarcó que la explotación de productos como el petróleo generan pago de regalías.

- Ley 141 de 1994, mediante la cual se estableció que las regalías correspondían al $20 \%$. Además fueron creadas las instituciones encargadas de regular la captación de regalías por parte del Estado, las reglas de liquidación, distribución y uso.

- Ley 756 de 2002, modifico la ley anterior y "estableció criterios de distribución de cálculo de regalías para los diversos productos mineros y los hidrocarburos y sus derivados" (Banco de la República de Colombia, 2012). 
- $\quad$ Decreto Ley 1760 de 2003, deroga el Decreto Le7 0030 de 1951 y el Decreto Ley 2310 de 1974, permitiendo la existencia cualquier tipo de contrato, en lo que respecta al sector petrolero.

- $\quad 2003$, se crea la Agencia Nacional de Hidrocarburos (en adelante ANH), con el propósito de relevar a Ecopetrol de su rol como entidad reguladora del sector. Permitiendo que la empresa se centre las actividades propiamente productivas del sector (Agencia Nacional de Hidrocarburos, 2014).

- $\quad$ En 2004, la ANH anunció que existe una nueva modalidad que contrato, en la que no es necesaria la participación de Ecopetrol.

- Decreto 1760 de 2003 convirtió a Ecopetrol en una sociedad pública por acciones, vinculada al Ministerio de Minas y Energía.

La legislación que regula la IED, se encuentra en el Estatuto de Inversiones Internacionales del País, Decreto 2080 de 2000. El Régimen Cambiario, se encuentra en la Resolución 8 de 2000 de la Junta Directiva del Banco de la República. En este régimen se incluyen normas especiales para el sector petrolero los cuales establecen un régimen cambiario especial (Banco de la República de Colombia, 2012, pág. 71). Según el Banco de la República, el régimen cambiario especial que aplica a sector petrolero "supone un fuerte respaldo financiero de la casa matriz, especialmente en las etapas iniciales de exploración y desarrollo de la capacidad de explotación y de transporte del crudo".

El efecto positivo de los cambios políticos internos en la producción petrolera como la adopción de políticas macroeconómicas orientadas al manejo adecuado del auge de estos recursos, uso de políticas fiscales y monetarias anti-cíclicas, así como las políticas de desarrollo que afectan al sector, tienen como objetivo incentivar la inversión de empresas privadas y/o públicas de acuerdo con las necesidades de cada proyecto (Unidad de Planeación Minero Energética, 2005). A su vez el aumento de costos de producción que se ha venido generando debido a la escasez de mano de obra calificada, maquinaria y servicios especializados y a la expansión del sector petrolero, estos 
factores determinan la capacidad que se pueda crear en las distintas regiones (Ramírez \& Cuéllar, 2013).

Para el Banco de la República (2013), la industria petrolera requiere de grandes cantidades de capital, así como de tecnología; es así que debido a la escasez relativa de estos recursos en la economía colombiana, se hace necesaria la IED para lograr el desarrollo del sector. No obstante, la inversión de capital nacional por parte de Ecopetrol luego de su fortalecimiento financiero, ha atenuado la dependencia en la IED (Banco de la República de Colombia, 2013). La participación de IED en el sector petrolero está incentivada por el precio internacional, como se ya fue señalado, así como por las políticas en las que opera el sector privado. La inversión extranjera se distribuye en actividad exploratoria (estudios sísmicos y perforación de pozos exploratorios), así como en infraestructura de transporte y producción (Banco de la República de Colombia, 2013).

A mediados de los años setenta, se desarrolló una política de autoabastecimiento y utilización adecuada y racional de los hidrocarburos, la implementación de esta política logró disminuir la tasa de deterioro de los campos existentes, así como mejorar la producción con el paso del tiempo (Unidad de Planeación Minero Energética, 2005). Es relevante recordar, que hacia finales de la década de los setenta, se presentó una crisis del sector petrolero a nivel mundial, que junto con una caída de la producción nacional, llevó al país a tener que importar petróleo y algunos de sus derivados (Unidad de Planeación Minero Energética, 2005).

El efecto negativo generado por esta situación política se ocasionó gracias al conflicto interno del país, pues como reporta la Unidad de Planeación Minero Energética (en adelante UPME) (2005), que en los años noventa se presentaron chantajes a los propietarios de la infraestructura de transporte de petróleo por parte de grupos al margen de la ley; así como atentados contra la infraestructura, generando además problemas ambientales y desestimulando la inversión en el sector. En años recientes la notable 
mejoría que se ha presentado en cuanto a la seguridad en todo el territorio nacional, ha aumentado la confianza de los inversionistas del sector petrolero (Coleman, 2012).

Usando la teoría institucionalista, en Colombia no existe una conjetura adecuada que explique el desarrollo de las estrategias petroleras dado que se basan en supuestos asociados al intercambio sin fricciones y sin problemas de información soportados en la competencia lo cual no es aplicable al desarrollo económico actual, en vista que que los conflictos que están ligados al orden público en el país afectan las decisiones empresariales del sector petrolero y por ende los costos de negociación con los inversores locales y extranjeros, desembocando en problemas institucionales que afectan a la sociedad y definen nuevos desempeños económicos que perturban la teoría de la producción.

Otra política favorable para la producción petrolera nacional es la Ley 963 de 2005, donde se establecen los Contratos de Estabilidad Jurídica. Este tipo de contratos, protege a las empresas nacionales como internacionales de los "cambios desfavorables en las leyes o reglamentos detallados en los contratos entre el gobierno y las empresas" (Coleman, 2012). Estos contratos pueden tener una duración de 3 a 20 años y se paga una prima anual de $1 \%$ respecto de la inversión, estableciendo reglas de juego que sustentándose en el institucionalismo genera incentivos que afectan el comportamiento de los individuos y organizaciones que son conformadas por los mismos, para componer mercados más eficientes y mejoras en los niveles de producción en el sector petrolero.

El impacto que estas políticas en la macroeconomía en variables como la inflación, PIB, y balanza de pagos genera flujo de ingresos del sector productor de petróleo, que se muestra en la IED que ha recibido el sector, con una participación de $9 \%$ del total de la IED que ha recibido Colombia, entre 2006 y 2010 (Coleman, 2012). Según Coleman, en el 2006 se identificó que uno de los incrementos de IED más altos esta dado en el sector 
petrolero, debido a los altos precios internacionales de petróleo y los cambios en beneficio de los inversionistas en los contratos.

\subsection{Factores propios del sector.}

Según Lajous (2006), el ciclo de los sistemas petroleros consiste en una etapa de "descubrimientos sustantivos", que dan inicio a la etapa de producción, que luego de llegar a su punto más alto empieza a decaer. Por lo anterior, mantener la exploración en busca de nuevos yacimientos, debe ser una parte fundamental de la industria petrolera. Este autor también indica que, a nivel mundial, cada vez es más difícil y por ende más costoso encontrar nuevo yacimientos de petróleo (Lajous, 2006).

Las reservas de petróleo son la base de la producción, por lo que es importante resaltar que durante el 2013 Ecopetrol tuvo un índice de reposición de reservas de 139\%. Esto indica, que por cada barril de petróleo producido, las reservas probadas aumentaron en 1.39 barriles, manteniendo la relación reservas/producción (vida media de las reservas) en 8.1 años (Ecopetrol, 2014). Esto según la UPME (2005) significa que el autoabastecimiento, cada año será más corto, por la "declinación propia de los campos". Lo anterior puede corresponder a que creció más la producción que la incorporación de reservas, planteando un reto en materia exploratoria, porque solo en la medida en que Colombia tenga mayores descubrimientos se podrá sostener el nivel de producción por encima del millón de barriles

Según Ecopetrol (2014), se tiene proyectado que para el período comprendido entre 2014 y 2020 se realice una inversión de US\$68.580 millones. Esta inversión se distribuirá 
en exploración y producción (81\%), modernización de las refinerías de Barrancabermeja y Cartagena (10\%) y fortalecer la red nacional de transporte y evacuación (9\%).

El mercado internacional petrolero ha sido afectado por el aumento del precio del crudo, los países especuladores y la crisis financiera. El aumento del precio ha permitido que las compañías petroleras tengan una gran ganancia en los últimos años, incrementar su inversión y apalancar proyectos que en algún momento con bajos precios no eran viables económicamente, por lo tanto la bonanza en los precios del petróleo debe servir al país para fortalecer su infraestructura productiva en este sector y anticiparse a las posibles perturbaciones que a futuro puedan generar un choque de oferta.

La inestabilidad política y financiera generada a partir de la crisis mundial del 2008, ha hecho que países como los miembros del G8 (Estados Unidos, Inglaterra, Alemania, Francia, Italia, Canadá, Japón y Rusia) y otros más, tengan la necesidad de invertir en nuevos proyectos energéticos en el sector de la extracción de hidrocarburos que permitan abastecer la seguridad energética y el desarrollo estable en el período posterior a la actual crisis económica global.

Lo anterior afectó positivamente a Colombia, ya que en el primer bimestre de 2012, el flujo IED hacia el país llegó a los 2.740 millones de dólares, lo cual equivale a un incremento del 24,8\%, según los datos de la Balanza cambiaria del Banco de la República

Bajo este escenario, Colombia se ha convertido en uno de los países que más ha recibido Inversión Extranjera Directa (IED) en la región, ha demostrado con cifras las expectativas que tiene de convertirse en un punto obligado a la hora de pensar en invertir de manera segura para el futuro. A pesar de la gran recesión que atraviesa la aldea global y de las bajas en las tasas de inversiones en muchas regiones en desarrollo, Colombia ha logrado en el 2010 aumentar la IED en los primeros cuatro meses un 22,9\% 
con relación al mismo período que el año anterior. Además según el ranking del Banco Mundial del "Doing Business" Report (Reporte Haciendo Negocios), Colombia está ubicado en el puesto 39 a nivel mundial y 3 en América Latina en el año 2009.

El sector petrolero requiere estar a la vanguardia de tecnología y Colombia se encuentra abierta y alineada con este desarrollo. Se ha planeado la implementación de tecnologías en la perforación, en el trazado de oleoductos, herramientas de investigación, aplicación de métodos de recuperación secundaria y terciaria, yacimientos no convencionales y crudos pesados que han optimizado tiempos y costos de exploración y explotación de hidrocarburos. Desde el punto de vista ecológico, el país está comprometido con el Medio Ambiente, ya que viene reduciendo los índices de afectación ecológica y ambiental donde operan los campos petroleros, mediante una regulación estricta y un fuerte seguimiento a todas las compañías operadoras.

Por otro lado, las compañías operadoras cuentan con personal calificado en recursos ambientales para asegurar que el daño sea mínimo y que se cumplan con las estrictas medidas de seguridad ambiental y ecológica.

\subsection{El sector industrial y sus competidores.}

El sector petrolero en Colombia influencia cada vez más la economía del país gracias a los primeros lugares que ocupa en la generación de divisas y al aumento de su participación en el Producto Interno Bruto (PIB) del país, pues entre el 2002 y el 2008 el PIB del sector petrolero se duplicó, pasando de $\$ 8,1$ miles de millones $(3,5 \%$ del PIB país) a $\$ 23,3$ miles de millones en el 2008 (4,9\% del PIB total), lo cual se puede apreciar en la Figura 3-2. 
Figura 3-2. Participación del sector minero y petrolero en el PIB de Colombia

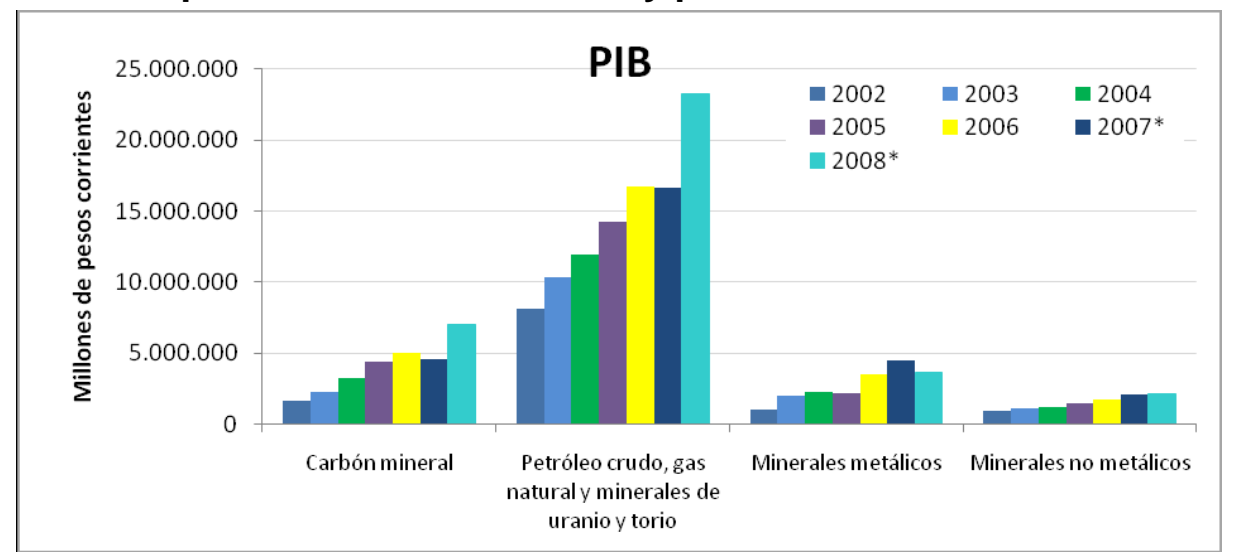

Fuente: Sector Minero y Petrolero en Colombia. (DANE, 2012).

Así mismo, el sector de minas e hidrocarburos se ha destacado por afectar positivamente a la variación del PIB Nacional, tal y como se observa en la

Figura 3-3, donde estos sectores ayudan a que en el 2009 Colombia fuera uno de los

pocos países del mundo que lograra registrar un crecimiento positivo de su economía (DANE, 2012).

Figura 3-3. Participación del sector minero y petrolero en el PIB de Colombia

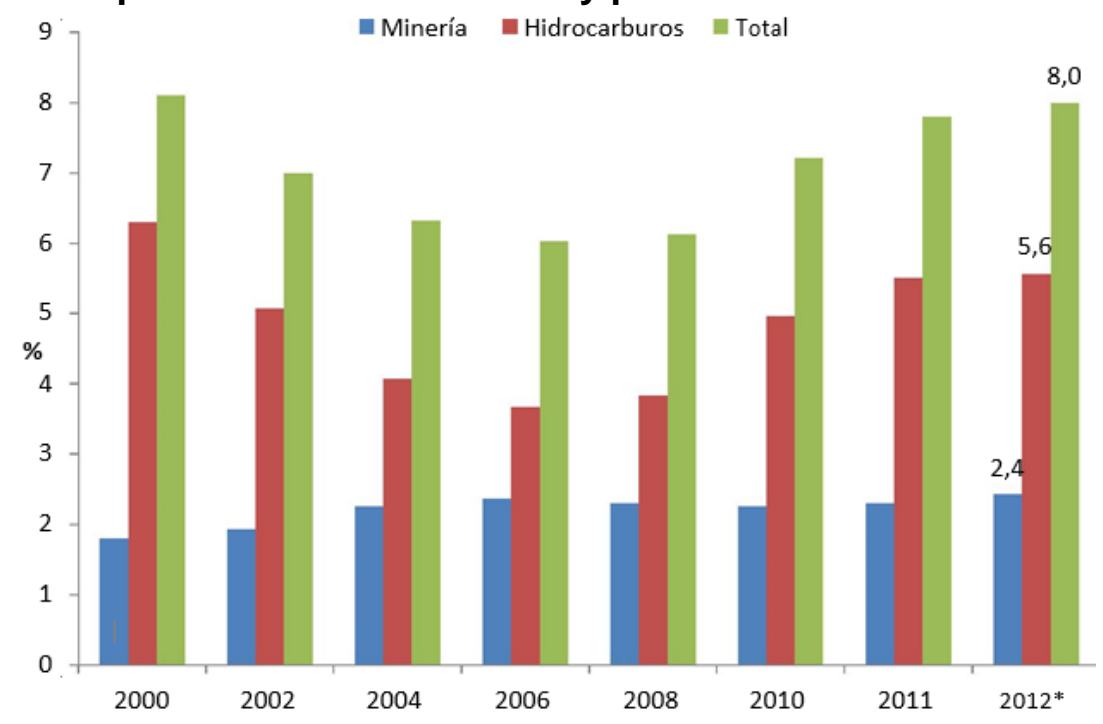


Fuente: Sector Minero y Petrolero en Colombia. (DANE, 2012).

Estas cifras son fiel reflejo de los incentivos ofrecidos por el Gobierno Nacional mediante el cual se otorgaron exenciones arancelarias a las importaciones de maquinaria, equipo y repuestos que se destinaran a la explotación, transformación y transporte asociada a la actividad de minería y a la explotación, transporte (por ductos) y refinación de hidrocarburos (Decreto 4743 del 30/12/2005).

El beneficio social y económico para el país ha sido notable, pues estos sectores incrementaron en forma sostenida sus aportes a los ingresos del Gobierno Central por concepto de impuestos y aportes a las regiones especialmente por regalías (DANE, 2012), en vista que estas son una fuente de financiación para el desarrollo territorial, que aportan al desarrollo social a través de instituciones sólidas (transparencia, efectividad, equidad y sostenibilidad).

\subsection{Análisis estructural del sector petrolero.}

A continuación se analizará la estructura del sector petrolero siguiendo el modelo de las cinco fuerzas de Porter (D’Alessio, 2008), especificando las principales características del sector en cuanto a poder de negociación de los proveedores, poder de negociación de los clientes, amenaza de los productos sustitutos del petróleo, entrada de nuevos competidores y rivalidad entre las compañías competidoras, lo anterior permite conocer las fuerzas más oportunas amenazadoras que enfrenta el petróleo en Colombia, entender los determinantes de la rentabilidad posible, el atractivo del sector y las tendencias estructurales a través de las cinco fuerzas que actúan en contra de la rentabilidad del sector, que afectan el grado de competencia, por ende las posibilidades de beneficio de un sector (Rivalidad entre competidores actuales, Amenaza de competidores potenciales, Poder de negociación de proveedores, Poder de negociación de clientes y Amenaza de los productos substitutos). 


\subsubsection{Poder de negociación de los proveedores.}

El sector petrolero lo componen dos grandes grupos, i) las Empresas Operadoras, las cuales tienen a su cargo la operación de los campos petrolíferos, generalmente en asociación con la Empresa Colombiana de Petróleos (Ecopetrol) para la operación y explotación de hidrocarburos; ii) las Empresas de Servicios, encargadas de ofrecer un portafolio de productos y servicios a las operadoras para llevar a buen fin la exploración y explotación de los campos. Para nuestro análisis, estas últimas serán consideradas como proveedores.

Actualmente en Colombia existe un amplio mercado de proveedores del sector petrolero en cuanto el país ha abierto desde hace muchos años las puertas a empresas extranjeras que facilitan a las operadoras productos y servicios tecnológicamente flexibles y a precios competitivos en el mercado nacional. En ese sentido, la competencia en este mercado es muy fuerte y habitualmente sobresalen las empresas más grandes debido a su amplio portafolio de productos y servicios, así como estructura de costos/precios, nuevos paradigmas de producción se sustentan en un grupo de tecnologías nuevas, conformadas por conocimientos y experiencias aplicables al diseño y fabricación de bienes y servicios, siendo así más competitivo el petróleo fomentando costos óptimos de producción, mayor confiabilidad en la operación y al dar la solución a un problema específico del cliente.

A manera de referencia:

En 2008, Schlumberger Surenco y Halliburton se consolidaron como líderes en el ranking de empresas de servicios petroleros en Colombia, mientras que Baker Hughes e Ismocol le acortaron distancias a SAI. Las ventas de Schlumberger Surenco fueron $\$ 760.472$ millones (aproximadamente US\$387 millones) y aumentaron $42,4 \%$ frente a 2007 . A su vez, las de Halliburton Latin America crecieron $48 \%$ al sumar $\$ 589.713$ millones (aproximadamente US $\$ 300$ millones). Ambos líderes sobresalieron por su dinamismo. San Antonio Internacional (SAI) conservó el tercer puesto con ventas de $\$ 367.008$ millones (aproximadamente US $\$ 187$ millones) y un incremento de $17 \%$. Pero Baker Hughes de Colombia con \$276.027 millones (aproximadamente US\$140 millones) e Ismocol con $\$ 274.693$ 
millones (aproximadamente US\$140 millones) tuvieron mayores crecimientos, de 67,2\% y 155,6\%, respectivamente. (La Nota Económica, 2009)

Se muestra una superioridad de empresas multinacionales en el mercado de servicios petroleros en el país. El poder de negociación de los proveedores es bajo debido a la gran oferta de empresas de servicios -tanto nacionales como extranjeras- , dándole la ventaja a las compañías operadoras quienes pueden aumentar sus exigencias de calidad, servicio, garantía, tecnología, etc. al tiempo que pueden presionar por precios bajos.

Como excepción, se encuentran algunas pocas compañías de servicios (Suministros Tecnicos Petroleros Ltda, Drillmec Inc. Sucursal Colombia, Venefilter, Qmax Solutions Colombia, Gds Colombia S.A.S.), que ofrecen tecnologías nuevas sin competencia en el país, las cuales tendrán un mayor poder de negociación sobre las operadoras, en cuanto mantengan esa ventaja competitiva, que en la mayoría de ocasiones no se extiende por mucho tiempo.

\subsubsection{Poder de negociación de los compradores.}

Los compradores se dividen en dos grandes grupos, los nacionales y los internacionales. Centraremos el análisis en las ventas nacionales, que representan una mayor porción, de acuerdo a las cifras publicadas por Ecopetrol en su Informe Anual 2009.

Asimismo, asumiremos que los compradores nacionales son los consumidores del producto final, para este caso los derivados del petróleo, los cuales son productos procesados en refinerías usando como materia prima el petróleo, la cadena de producción del petróleo inicia con la sísmica continua con la perforación exploratoria, proceso y bombeo, refinación, transporte y comercialización. Según la composición del crudo y la demanda, las refinerías pueden producir distintos productos derivados del petróleo, sin embargo la mayor parte del crudo es usado como materia prima para 
obtener energía, por ejemplo la gasolina,. Para nuestro análisis, tomaremos como producto final los principales combustibles utilizados para obtener energía.

De acuerdo a lo anterior, el poder de negociación de los compradores de petróleo es relativamente bajo, ya que los precios de los combustibles están regulados por el Gobierno Nacional, dándole al consumidor la mínima posibilidad de negociar el precio de compra. Sin embargo, la dura competencia entre los distribuidores de combustibles ha influido en la fijación de precios al consumidor final (especialmente a los consumidores de gasolina y diesel de las estaciones de servicio) permitiéndoles a estos establecimientos competir por precios, en favor del consumidor final. Sin embargo, es de anotar que a pesar de esto, los precios de los combustibles en Colombia son altos en comparación con los otros países de la región, el Ministerio de Minas y Energía fija los precios de los productos derivados del petróleo (producción y distribución), con excepción del Gas Licuado del Petróleo (GLP), que tasa la Comisión de Regulación de Energía y Gas-CREG. Los productos regulados por el Ministerio de Minas y Energía son la gasolina corriente, gasolina corriente oxigenada y el ACPM, para los demás productos derivados del petróleo los precios son fijados por Ecopetrol y cada uno de los agentes de la cadena, de acuerdo a las condiciones del mercado.

\subsubsection{Amenaza de los productos sustitutos del petróleo.}

Debido al alto nivel de precios del petróleo y al hecho de que sea un recurso no renovable, se ha intensificado en los últimos años la búsqueda de energías alternativas y limpias (Misiones On Line, 2007). Aunque las investigaciones para desarrollar productos sustitutos avanzan a buen ritmo en todo el mundo y ya existen comercialmente nuevos combustibles, la humanidad seguirá dependiendo del petróleo aún por muchos años más. La razón de lo anterior obedece a que el petróleo no sólo es gasolina y ACPM.

En la vida cotidiana, en todo el mundo se usan los derivados del petróleo para producir telas, hilos, alfombras, muebles modulares, cepillos de dientes, medias veladas y hasta el labial que usan las mujeres. Y es que son 
más de 3.000 los productos de uso diario que se obtienen del petróleo. Por ejemplo, los plásticos, el aceite para bebé, el asfalto, las tintas y los jabones tienen derivados del petróleo. Incluso, el crudo es materia prima para la elaboración de aceros, entre otros productos. (Misiones On Line, 2007, pág. 2)

Por otro lado, el petróleo satisface el $40 \%$ del consumo mundial de energía primaria, seguido por el carbón y el gas natural con participaciones de $27 \%$ y $23 \%$ respectivamente. Esto indica que más del $60 \%$ del consumo mundial de energía primaria la cual es toda forma de energía disponible en la naturaleza antes de ser convertida o transformada, se satisface con hidrocarburos (petróleo y gas). Sin embargo al ser una fuente energética no renovable, ya se están mostrando claras señales de su agotamiento a nivel de las reservas mundiales y de su ritmo productivo. En la actualidad se estima que las reservas comprobadas de petróleo pueden durar los próximos 40 años, según un informe del grupo BBVA que se realizó con el apoyo de la British Petroleum (Misiones On Line, 2007).

En conclusión, se vislumbra una clara amenaza de los productos sustitutos en el corto y mediano plazo debido a la utilización actual del petróleo y a las reservas internacionales que se poseen actualmente. Sin embargo en materia de petróleo, las reservas incorporadas al balance nacional para el año 2012 provienen en su mayoría (un 67\%) de los recobros secundarios o revaluaciones en los campos (Rubiales, Castilla Norte, Quifa Sur, La Cira Infantas y Yariguies Cantagallo), el porcentaje restante corresponde a nuevos hallazgos, los campos que mayores aportes a las reservas fueron Acacías, Caño Sur; Sabanero, Moqueta, Zopilote y Copa.

\subsubsection{Ingreso potencial de competidores al mercado.}

El ingreso de nuevas empresas operadoras al mercado representa una amenaza a las compañías actuales en razón al auge petrolero que se vive en Colombia y a las exigentes y retadoras metas que se ha impuesto el Gobierno Nacional para convertir al país en uno de los grandes jugadores del sector a nivel internacional, requiriendo cada vez más mayor inversión en el sector y mayor exploración y explotación de hidrocarburos. 
A pesar de las barreras de entrada al mercado que tiene el país, las grandes empresas multinacionales han sabido superarlas gracias a su alta liquidez y al poder que ejercen sobre los gobiernos en virtud a sus elevadas inversiones y a la generación de empleo que favorece a las naciones y a sus pobladores

\subsubsection{Rivalidad entre las compañías competidoras.}

La rivalidad en el sector petrolero se evidencia tanto en las empresas operadoras como en las compañías de servicios. Para el primer caso, la competencia es alta debido a las arduas negociaciones que se deben tener con el Gobierno para obtener la asignación de un determinado bloque o campo petrolífero, por lo que las empresas están en constante competencia para "ganar" el derecho a explorar y explotar una zona específica. Por otro lado, las compañías de servicios están en constante rivalidad en vista que deben participar constantemente en licitaciones lanzadas por las empresas operadoras quienes buscan siempre la mejorar calidad al mejor precio, por lo que generalmente son las grandes compañías de servicios las que se quedan con los negocios más grandes.

\subsection{Matriz de perfil competitivo}

Según el análisis de las cinco fuerzas de Porter se han identificado siete factores clave de éxito para el sector petrolero, los cuales nos han permitido comparar los sectores petroleros de tres países de la Región Andina, considerados como competidores dentro del sector de hidrocarburos en Latinoamérica.

La Tabla 3-1 presenta la Matriz de Perfil Competitivo (MPC) donde se comparan los sectores petroleros de tres naciones pertenecientes a la Región Andina: Colombia, Venezuela y Ecuador, la comparación se basa en que el territorio Colombiano contiene zonas de transición entre los ambientes geotécnico del sur del caribe comparables a las regiones comprendidas entre Surinam y el bloque de Maracaibo de los cuales forman 
parte las cuencas del Catatumbo, Valle inferior del Magdalena y la Guajira, además de contextos geotécnicos de la orogénesis Andina las cuales involucran las cuencas subandinas a los largo de América del sur.

Tabla 3-1. Matriz del Perfil Competitivo del Sector Petrolero en Colombia 2013

\begin{tabular}{|c|c|c|c|c|c|c|c|}
\hline \multirow[b]{2}{*}{ FCE } & \multirow[b]{2}{*}{$\begin{array}{c}\text { Pes } \\
0\end{array}$} & \multicolumn{2}{|c|}{$\begin{array}{l}\text { Sector } \\
\text { Petrolero } \\
\text { Colombia }\end{array}$} & \multicolumn{2}{|c|}{$\begin{array}{c}\text { Sector } \\
\text { Petrolero } \\
\text { Venezuela }\end{array}$} & \multicolumn{2}{|c|}{$\begin{array}{l}\text { Sector } \\
\text { Petrolero } \\
\text { Ecuador }\end{array}$} \\
\hline & & Valor & $\begin{array}{c}\text { Pond } \\
\text {. }\end{array}$ & Valor & Pond. & Valor & Pond. \\
\hline $\begin{array}{l}\text { 1. Estabilidad legal del país que } \\
\text { garantice inversiones a largo plazo }\end{array}$ & 0.2 & 4 & 0.8 & 1 & 0.2 & 3 & 0.6 \\
\hline 2. Inversión en el sector & 0.2 & 3 & 0.6 & 4 & 0.8 & 2 & 0.4 \\
\hline $\begin{array}{l}\text { 3. Reservas de petróleo (producción } \\
\text { a largo plazo) }\end{array}$ & 0.15 & 2 & 0.3 & 4 & 0.6 & 2 & 0.3 \\
\hline $\begin{array}{l}\text { 4. Producción de } \\
\text { (capacidad productiva) }\end{array}$ & 0.15 & 3 & 0.45 & 4 & 0.6 & 3 & 0.45 \\
\hline $\begin{array}{l}\text { 5. Ubicación geográfica (costos de } \\
\text { transporte) }\end{array}$ & 0.10 & 4 & 0.4 & 4 & 0.4 & 3 & 0.3 \\
\hline $\begin{array}{l}\text { 6. Planes de crecimiento de la } \\
\text { petrolera estatal }\end{array}$ & 0.10 & 3 & 0.3 & 2 & 0.2 & 2 & 0.2 \\
\hline 7. Acceso a proveedores de calidad & 0.10 & 4 & 0.4 & 3 & 0.3 & 4 & 0.4 \\
\hline TOTAL & 1.00 & & 3.25 & & 3.1 & & 2.65 \\
\hline
\end{tabular}

Fuente: elaboración propia.

Los resultados del análisis muestran a Colombia en primer lugar en competitividad con un valor de 3.25, seguido por Venezuela con 3.1 y Ecuador con 2.65. Esto debido en gran medida a la estabilidad legal que se mantiene en Colombia desde los últimos ocho años y a las medidas que ha tomado el Gobierno Nacional para promover la inversión extranjera, especialmente la entrada de capitales de la industria petrolera. Por otro lado, la empresa estatal colombiana Ecopetrol tiene los planes más ambiciosos de crecimiento en América Latina junto con Petrobras de Brasil, en comparación con los planes de crecimiento que tienen actualmente PDVSA y Petroecuador (Portafolio, 2010). 


\subsection{Evolución del sector en los años 2010 a 2012}

\subsubsection{Entorno internacional.}

Según la BBC existen 7.000 millones de habitantes en el planeta y se estima que a 2050 la cifra llegará a 9.000 millones, demandando así un aumento en el suministro de energía, calculada en el orden de 30\% sobre los niveles actuales (E. I. A., 2013). Los altos precios de los crudos al final de la primera década de este siglo, incrementados en 2011 por la suspensión de suministro de Libia no fueron obstáculo para el alto crecimiento de 33,4\% del consumo mundial entre 2000 y 2012 (2.4\% anual). (Unidad de Planeación Minero Energética, 2013)

El crecimiento del consumo energético ha sido constante desde el año 2000, con una desaceleración significativa en 2009; desde 2010 se viene presentando reactivación con positivas tasas de crecimiento cercanas a los $5,6 \%, 2,4 \%$ y 2,1\%, respectivamente. En 2012, se presenta una disminución en la tasa de crecimiento por la ocurrencia de importantes eventos que afectaron la economía global y una mayor respuesta a los altos precios de los energéticos fósiles que motivaron tasas inferiores a la media mundial (E. I. A., 2013).

Adicional a los desastres naturales, en 2012 ocurrieron grandes oscilaciones en las expectativas de los inversionistas y la caída de la producción industrial, golpeada por los tardíos efectos de las políticas de estrechez económica, a causa de la transición en la economía estadounidense y de los trastornos financieros sufridos en la zona euro, además de los disturbios en algunos países árabes en lo que se denominó la "Primavera Árabe" así como de la reducción en la producción de crudos de Libia, influenciando notablemente los mercados mundiales de la energía. (Unidad de Planeación Minero Energética, 2013)

En la Figura 3-4 se presenta la proyección del consumo mundial de energía primaria. 
Figura 3-4. Proyección del consumo mundial de energía primaria

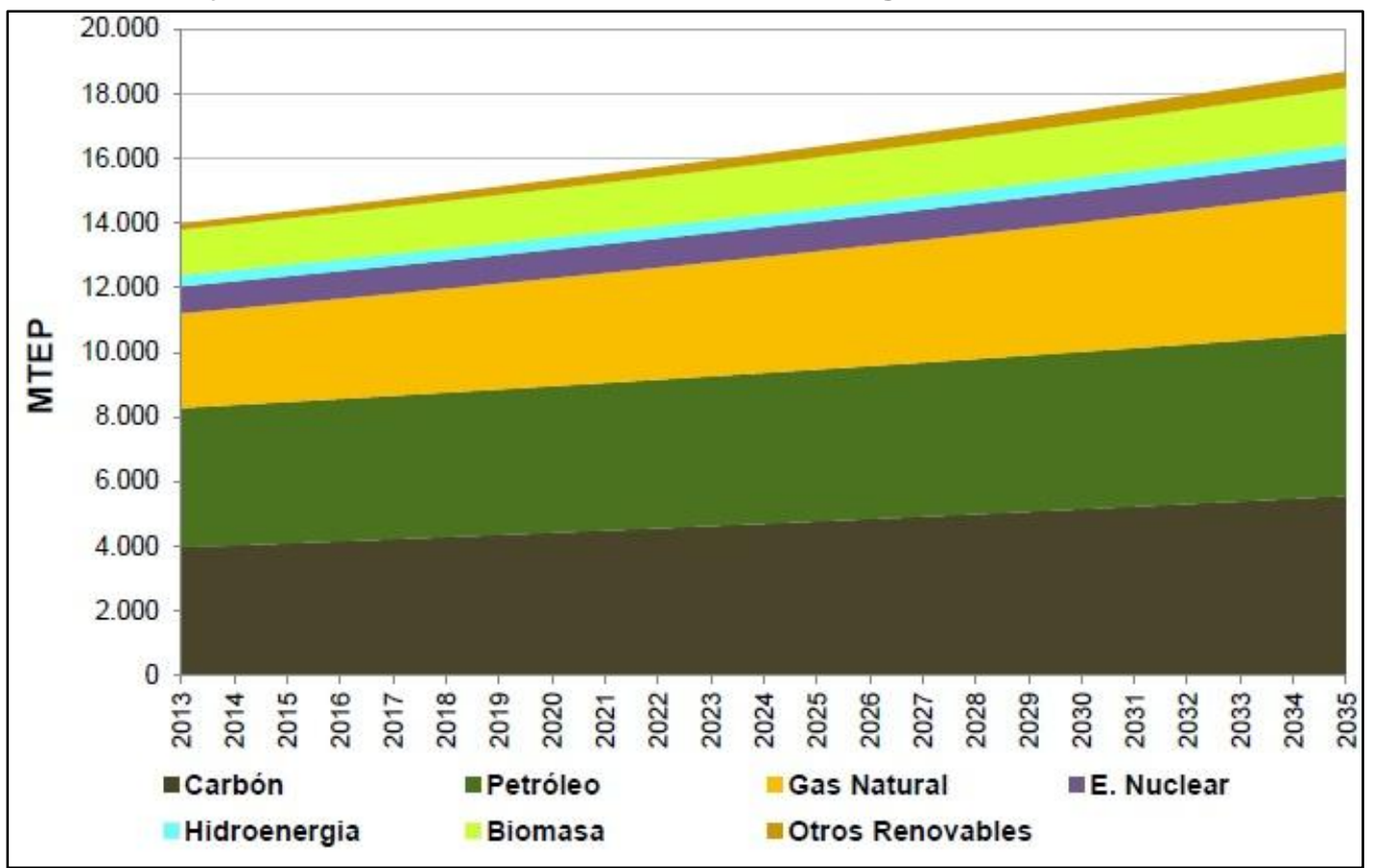

Fuente: World Energy Outlook (E.I.A., 2012)

Como se muestra en la Figura 3-4, la demanda de carbón aumenta cerca de 1.650 Millones de Toneladas Equivalentes de Petróleo MTEP, equivalente al 42,4\% en el período 2013 a 2035, con un crecimiento medio anual de 1,6\%, al pasar de 3.900 a 5.560 MTEP. El gas natural es la fuente de mayor tasa de crecimiento dentro de este tipo de energéticos, con 1,94\% y un aumento de 52,7\% al pasar de 2.880 a 4.400 MTEP al final del horizonte de estudio. En cambio, el petróleo es el energético fósil que registra la menor tasa de crecimiento con $0.74 \%$ promedio año, perdiendo tres puntos porcentuales con respecto a 2012, al alcanzar una participación relativa de $27 \%$ en 2035 y cediendo el primer lugar al carbón. (E.I.A., 2012)

Las cifras de consumo en 2012 alcanzaron los 89,7 millones de barriles por día, representando un incremento de $2 \%$ respecto a 2011 , variación superior al promedio calculado desde el año 2000, que en términos anuales ascendió a los 1,04 Millones de barriles por día MBPD, lo que significa 1,27\% promedio año. En cuanto a la evolución de los precios, el comportamiento en lo que va del Siglo XXI y hasta 2013, ha sido el que se presenta en la Figura 3-5. 
Figura 3-5. Precio spot de crudos marcadores

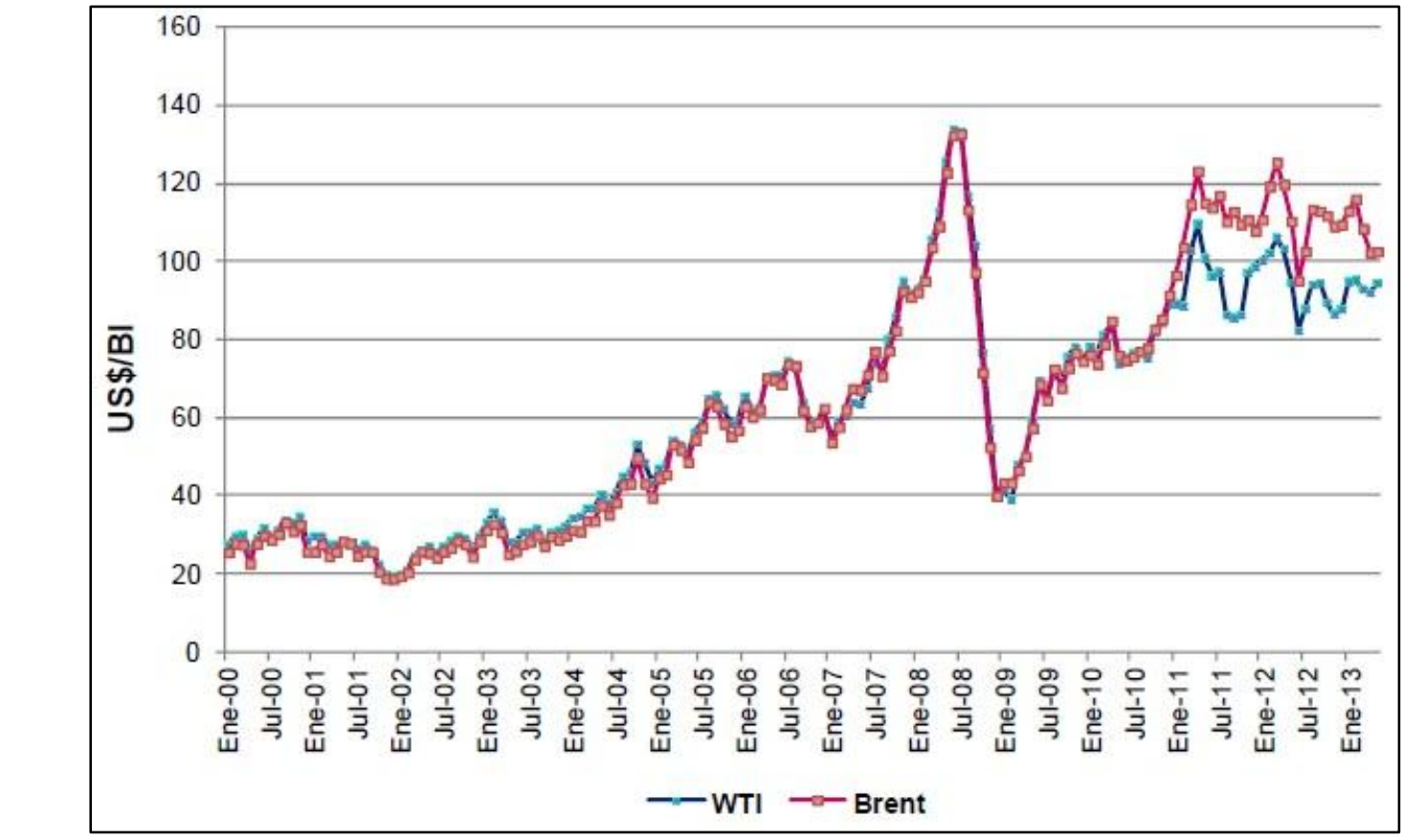

Fuente: (E.I.A., 2013)

A partir de la primera mitad de la década de 2000 los precios los crudos WTI y Brent comenzaron a separarse uno del otro, en favor del Brent, como consecuencia, por una parte, del comienzo de una rápida declinación de la producción en el Mar del Norte, en especial en los campos de Noruega y el Reino Unido. En 2012 los precios del crudo se vieron afectados por la incertidumbre asociada al comportamiento de la economía mundial derivada de los eventos geopolíticos, del crecimiento de la demanda en mercados emergentes, de la lenta recuperación de la demanda de los países industrializados y la volatilidad de los mercados financieros. (Unidad de Planeación Minero Energética, 2013).

En la Figura 3-6, por su parte, se presenta la evolución de las reservas mundiales de petróleo. 
Figura 3-6. Evolución de las reservas mundiales de petróleo.

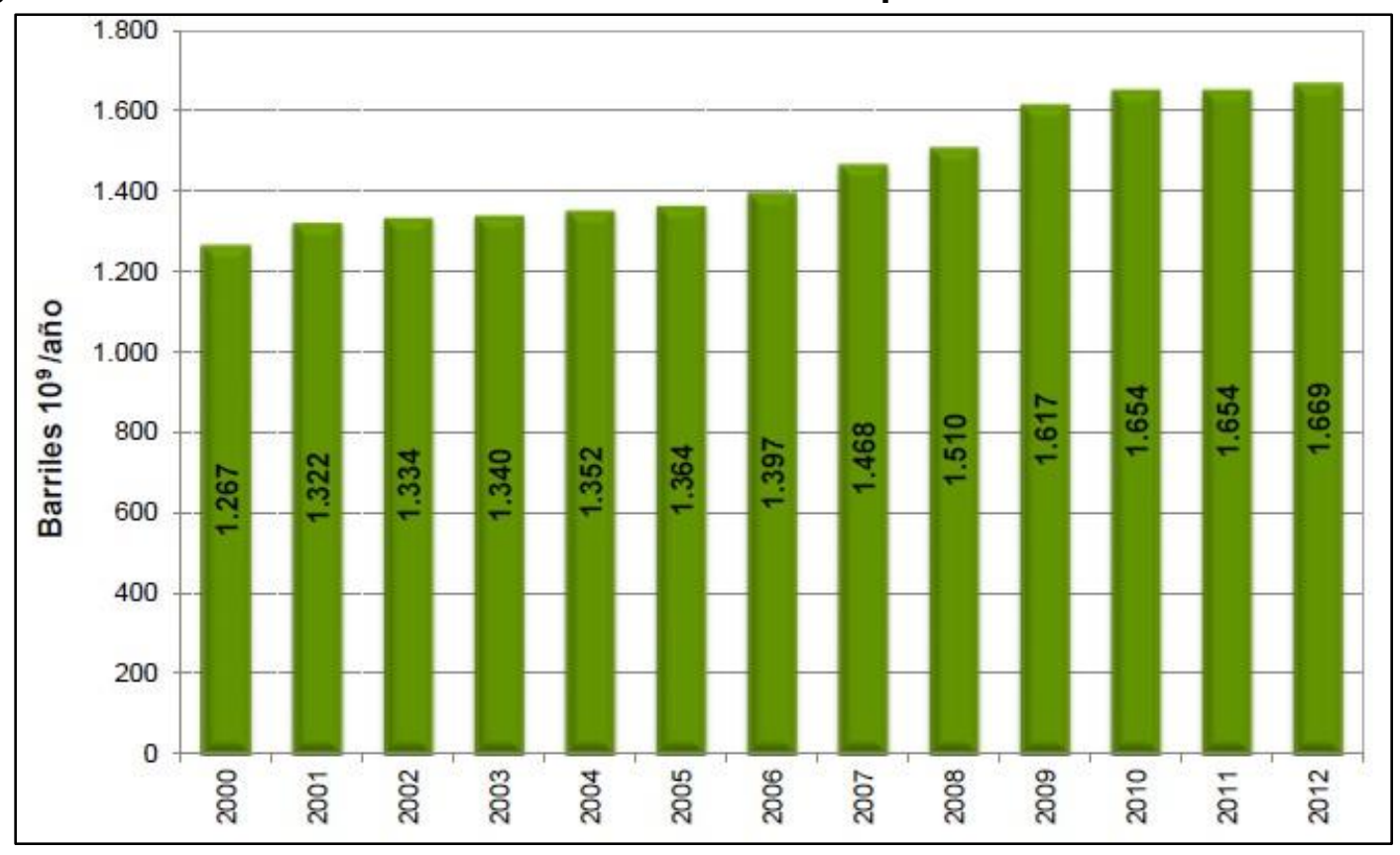

Fuente: World Energy Outlook (E.I.A., 2012)

Al finalizar 2012, las reservas probadas de crudo se calcularon en 1.669 miles de millones de barriles, según el BP Statistical Review (2013), 0,99\% más que en 2011, de las cuales el 72,6 \% pertenecen a los países de la OPEP y el restante $27,4 \%$ a los países fuera de la organización. El escaso aumento de 16,3 miles de millones de barriles en 2012 muestra una de las menores tasas en lo corrido del nuevo siglo, cuyo promedio anual se sitúa en 2,4\%. Los países que aumentaron sus recursos fueron en su orden India con 11,6 miles de millones, Iraq con 6,9, Irán que incluyó 5,8 y Estados Unidos que incorporó 4,1 miles de millones de barriles.

A su vez, la producción mundial de crudos en 2012 presentó un incremento porcentual de $3,1 \%$ con referencia al 2011, lo que equivale a 2,5 MBPD más en el mercado, como se muestra en la Figura 3-7. La producción totalizó un volumen que implica de 86,15 miles de barriles día, equivalente a $15,2 \%$ adicional a lo producido en el año 2000 , con una tasa de crecimiento medio anual de $1,2 \%$ en ese período. 
Figura 3-7. Producción mundial diaria de petróleo

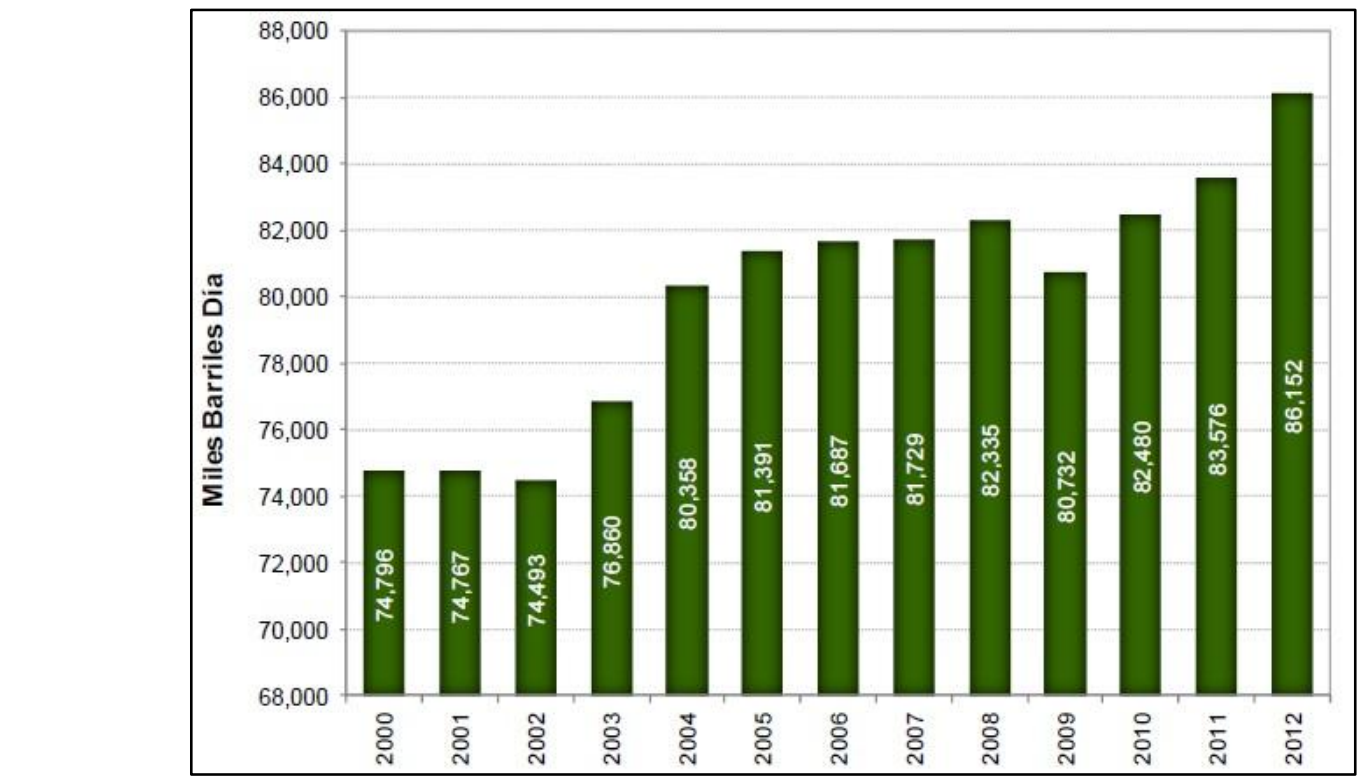

Fuente: BP Statistical Review (2013)

La región de Medio Oriente fue la de mayor producción con 28,2 millones de barriles diarios, es decir una contribución de $32,8 \%$ del total mundial y un incremento de $2,1 \%$ respecto a 2011. La zona muestra un crecimiento continuo con un aumento del aporte calculado en $20,2 \%$ para el período 2000 - 2012 mostrando un crecimiento medio de 1,5\% anual en mismo ciclo. (B. P., 2013). La evolución de las reservas fue la que se muestra en la Figura 3-8 
Figura 3-8. Reservas probadas de petróleo Centro y Suramérica

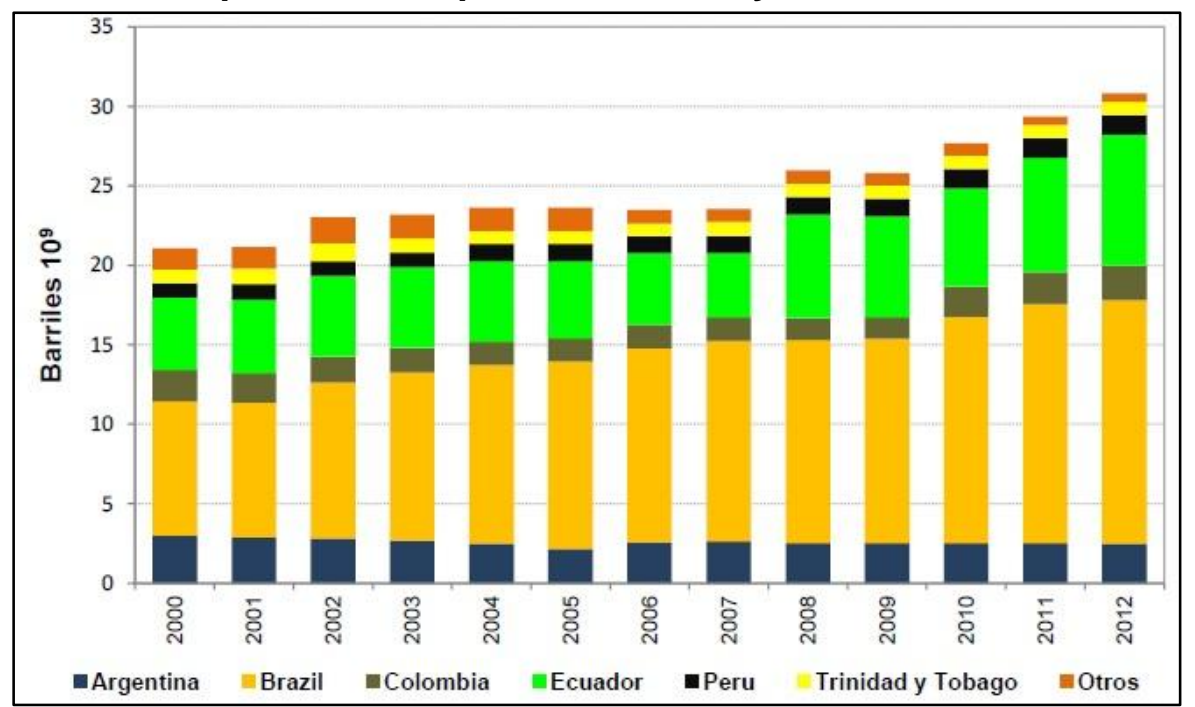

Fuente: BP Statistical Review of World Energy 2013

Entrando ahora al contexto de Latinoamérica, según las cifras reportadas por la British Petroleum (2013), al finalizar 2012 Argentina tenía reservas petroleras que le alcanzarían sin nuevos descubrimientos para 10,2 años; Brasil para 19,5; Colombia para 6,4; Ecuador para 44,6 y Venezuela para más de 200 años. A su vez, la capacidad regional de refinación alcanzó 5,9 millones de barriles día al finalizar 2012, contribuyendo con el 6,39\% del total mundial, cifra 8,8\% menor a la registrada en 2011 (B. P., 2013); las cifras de cada país se muestran en la Figura 3-9 
Figura 3-9. Capacidad regional de refinación

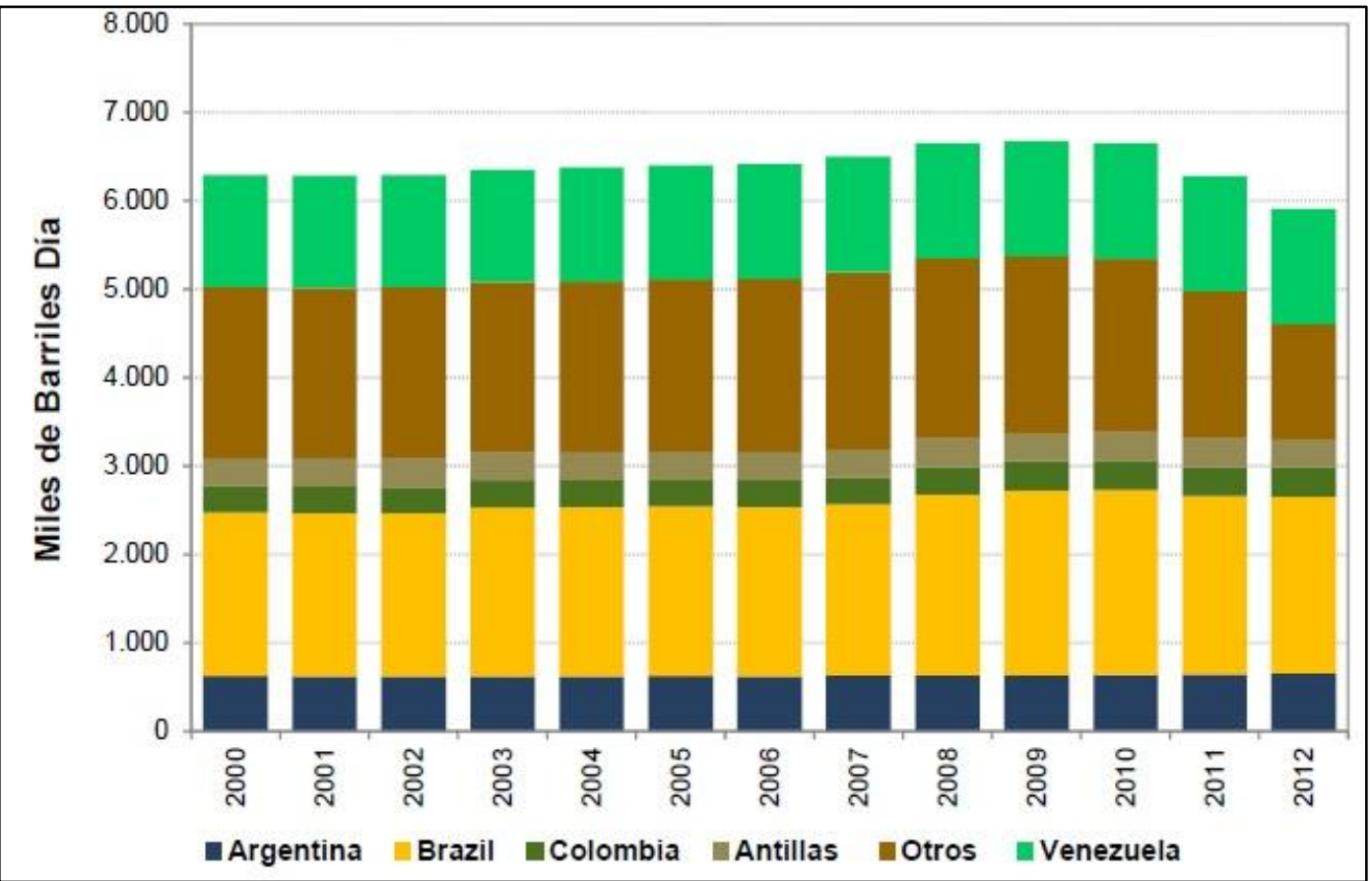

Fuente: BP Statistical Review of World Energy 2013

Entre los países con mayor capacidad de refinación, en el nivel inferior se encuentra Colombia con (0.33 millones de barriles y 4 plantas), le sigue Argentina con (0,65 millones de barriles día y ocho plantas), Venezuela (con 1,3 millones y seis plantas) y en el nivel superior Brasil (con 2 millones y 12 plantas); el resto de países de la región suma aproximadamente 1,3 millones de barriles día.

\subsubsection{Entorno nacional}

El análisis de las cifras internas relacionadas con las diferentes fuentes de energía y particularmente con el petróleo, se encuentra en primer lugar que, de manera individual, el gas natural es el energético cuyo consumo presenta la mayor tasa de crecimiento con $5,62 \%$ promedio año en el lapso 2000 - 2012 y con una adición de 0,19 millones de toneladas equivalentes de petróleo al volumen consumido durante 2000 , finalizando con 0,215 millones de Toneladas equivalentes de petróleo TEP, como se muestra en la Figura 3-10 (Unidad de Planeación Minero Energética, 2013). 
Figura 3-10. Consumos energéticos

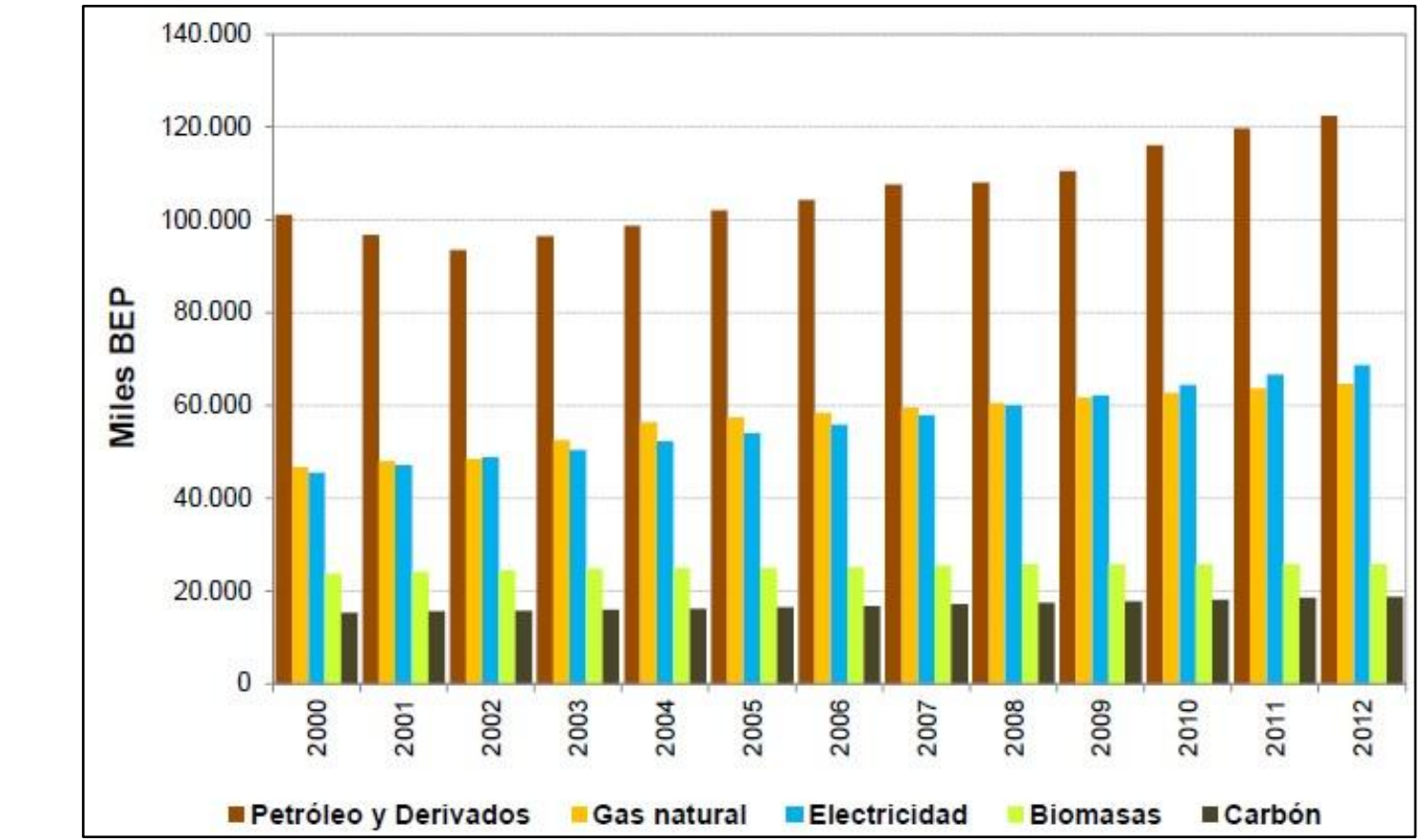

Fuente: UPME

Esto representa un aumento de $93 \%$ en el período 2000 a 2012, registrando disminución tan solo en el año 2009, cuando el país presentó la tasa más baja de PIB de los últimos 10 años, como consecuencia de la crisis económica vivida. Los derivados del petróleo son la principal fuente de abastecimiento del sector transporte, aun cuando hoy hacen parte de la oferta nuevos combustibles carburantes como el gas natural vehicular GNV los biocombustibles, cuya contribución es aún marginal. Factores como los precios de los combustibles destinados para el sector transporte, el desarrollo de sistemas masivos de transporte de pasajeros en las grandes ciudades, entre otros, han modificado sustancialmente la composición del consumo al interior de este sector, por lo que el diésel ha presentado tasas de crecimiento superiores a las del pasado, incrementando su participación en el mercado y por consiguiente, generando una regresión del consumo de gasolina. 
En materia de contratos de exploración, durante 2010 se llevó a cabo una nueva ronda en la cual se ofertaron 229 bloques ubicados en todas las cuencas del país y se logró la asignación de 78 bloques en cuencas emergentes y frontera. Así mismo durante 2012 se realizó la Ronda 2012, en el cual se asignaron áreas para la exploración y explotación de hidrocarburos con la oferta de 115 bloques costa afuera y tierra adentro, de las cuales se adjudicaron 50 bloques. El $84 \%$ de las adjudicaciones pertenecen a la modalidad de contratos de exploración y producción E\&P, con mayor concentración en la cuenca Llanos. Estos contratos generaron una evolución de la inversión extranjera directa que se grafica en la Figura 3-11

Figura 3-11. Inversión extranjera directa en petróleos

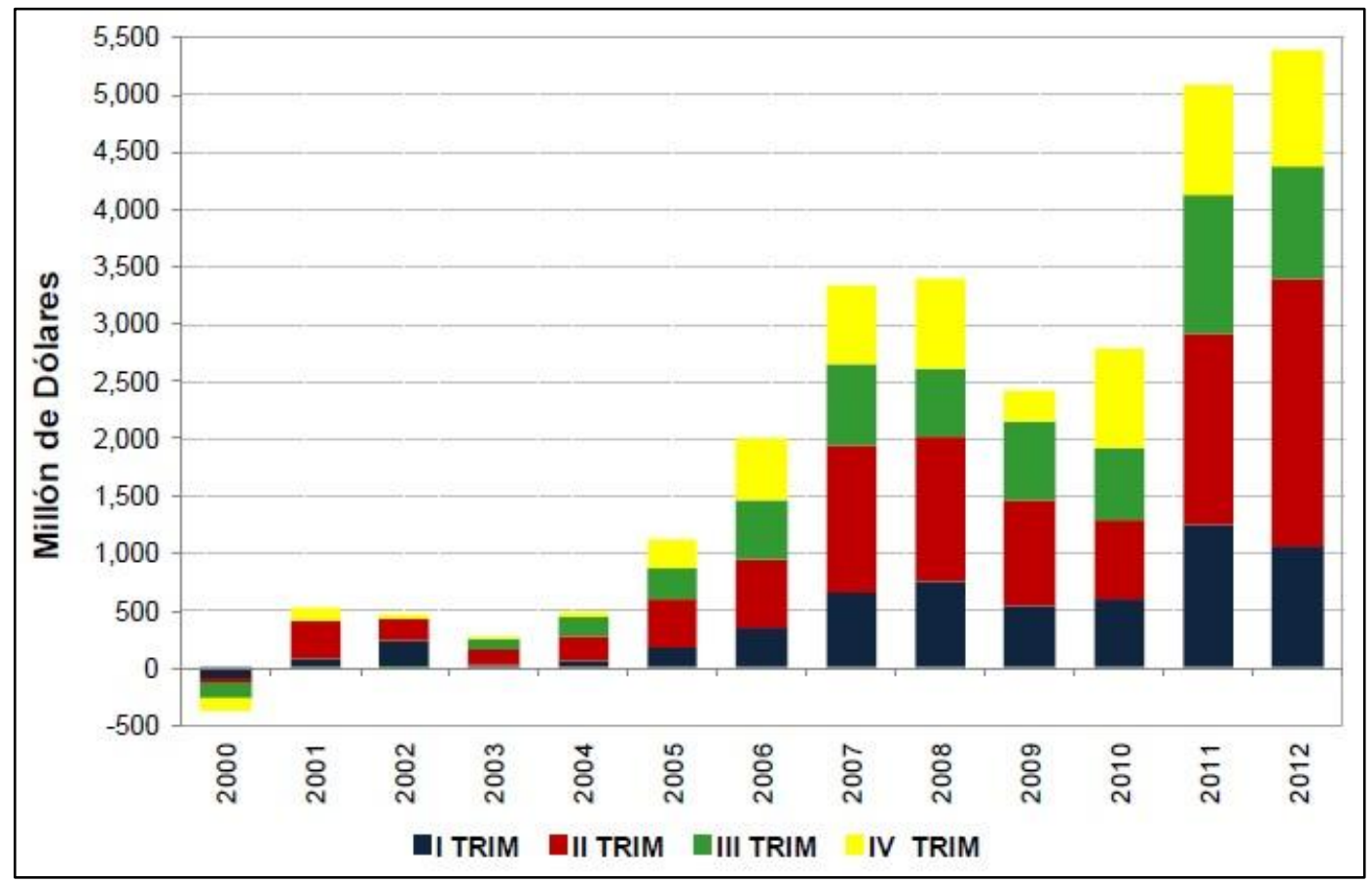

Fuente: Banco de la República Estadísticas. (2013)

Según lo reporta el Banco de la República (2013), las condiciones de la economía mundial y la economía doméstica han sido propicias para la realización de mayores inversiones, orientada en gran parte al crecimiento de la industria petrolera. Tal como lo muestra la Figura 3-11, la inversión ha venido presentando crecimientos importantes 
desde 2005, alcanzando en 2012 un aumento de 400\% respecto a ese año. Durante 2011 y 2012 se registraron cifras record de la inversión extranjera directa dirigida al sector de hidrocarburos, después de la disminución presentada en 2009 y 2010, producto de la desaceleración económica mundial.

Los flujos de recursos se aproximaron a los 5.083 y 5.389 millones de dólares en 2011 y 2012, correspondientemente, en tanto que en 2010 su valor llegó solo a 2.781, siendo el 2011 el de mayor tasa de crecimiento de los cinco últimos años (Banco de la República de Colombia, 2013). En la actualidad el $37 \%$ de la inversión que ingresa se centra en las diversas actividades de la industria de hidrocarburos, lo que la convierte en motor de desarrollo de esta industria, lo que ha permitido el crecimiento de la producción petrolera, que alcanzó el millón de barriles a finales de 2012, lo que equivale a un incremento de más de 500 mil barriles desde 2008.

La Figura 3-12 muestra la evolución de la actividad sísmica en Colombia en el periodo 2000/2012.

Figura 3-12. Evolución de contratos de actividad sísmica

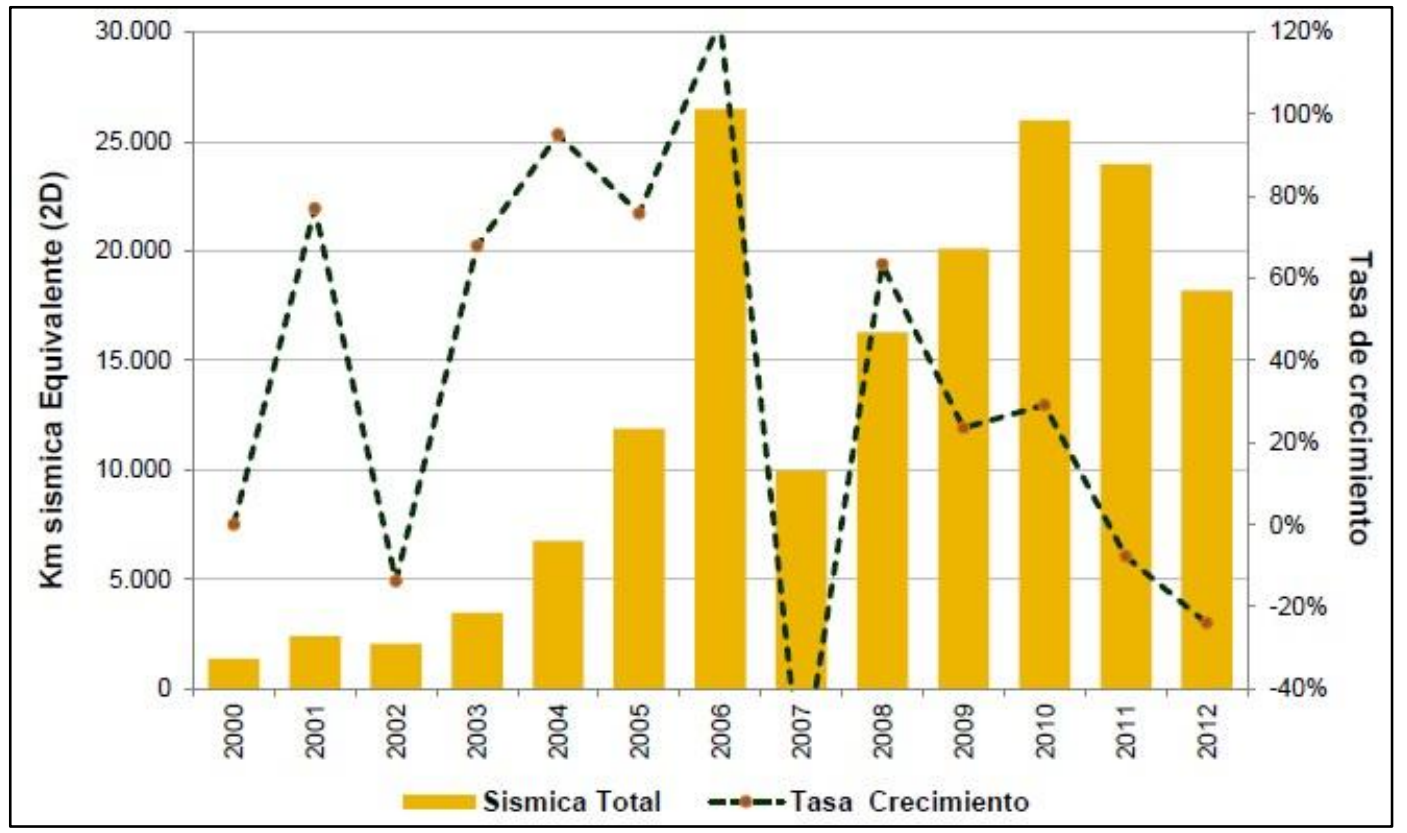

Fuente: ANH 
Desde la modificación del modelo contractual para la exploración de hidrocarburos, la actividad sísmica registra niveles ascendentes de manera sostenida y con el cual se estima un aumento significativo en los próximos años, con miras a ampliar la disponibilidad de recursos y, por tanto, la extensión del autoabastecimiento. (E. I. A., 2013). Gracias a esas actividades de exploración sísmica, las reservas presentaron la evolución que se muestra en la Figura 3-13

Figura 3-13. Reservas probadas de petróleo en Colombia

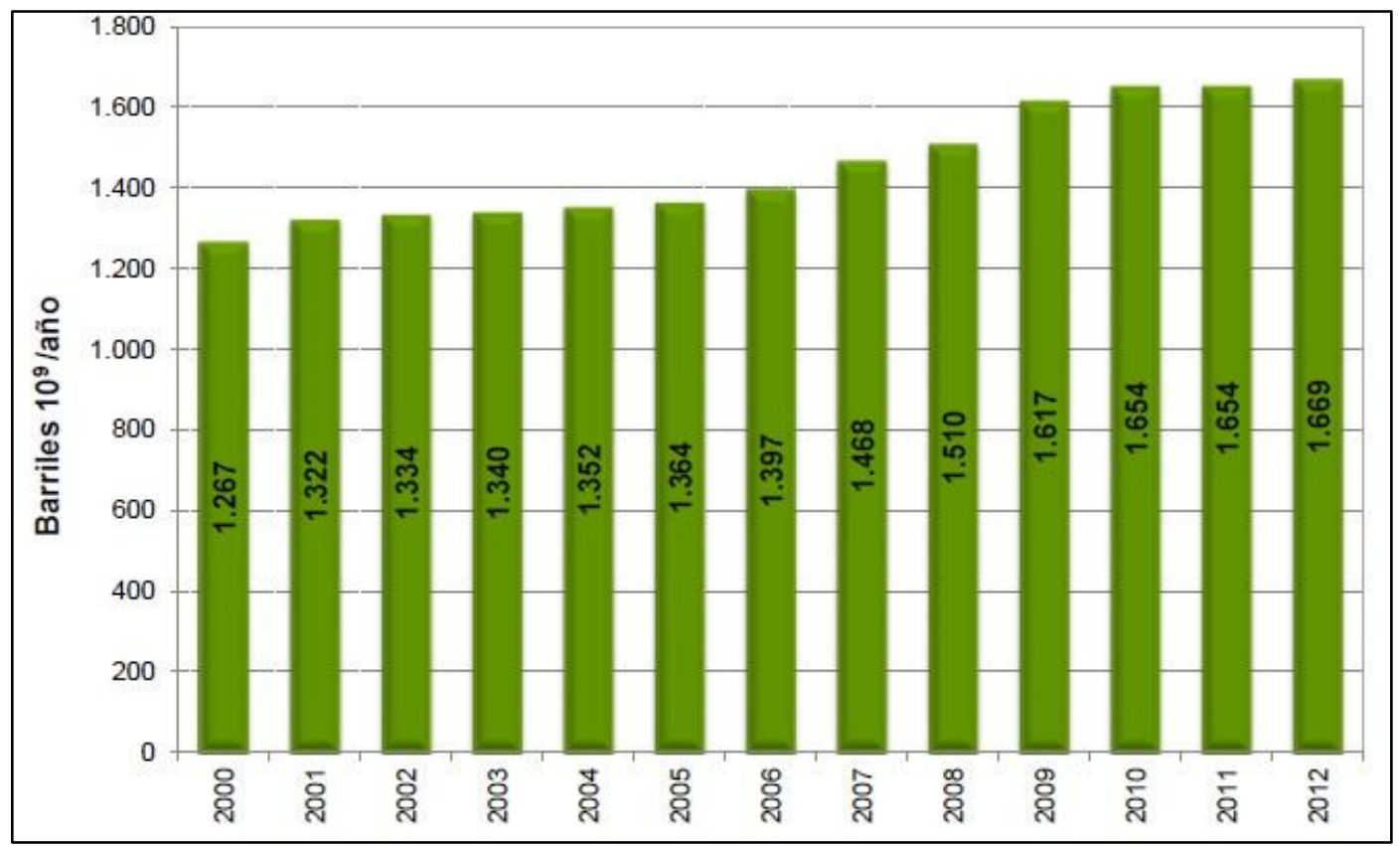

Fuente: Unidad de Planeación Minero Energética (2013)

Con cierre a 31 de diciembre de 2012, las reservas de petróleo mostraron un total de 2.377 millones de barriles que equivalen a un aumento de 5,2\% respecto de 2011 y en términos de volumen, 227 millones incluyendo los 345 millones de barriles producidos en 2012, que permite una reserva de 6,89 años a la tasa de producción del mismo 2012. Las reservas catalogadas como 3P, es decir el conjunto de probadas, probables y posibles al cierre del mismo 2012 sumaban 3.170 millones de barriles con una participación de las reservas probadas de $75 \%$, probables de $18 \%$ y posibles de $7 \%$. (Unidad de Planeación Minero Energética, 2013) 
En cuanto a la producción, la evolución se muestra en la Figura 3-14.

Figura 3-14. Evolución de la producción colombiana de petróleo

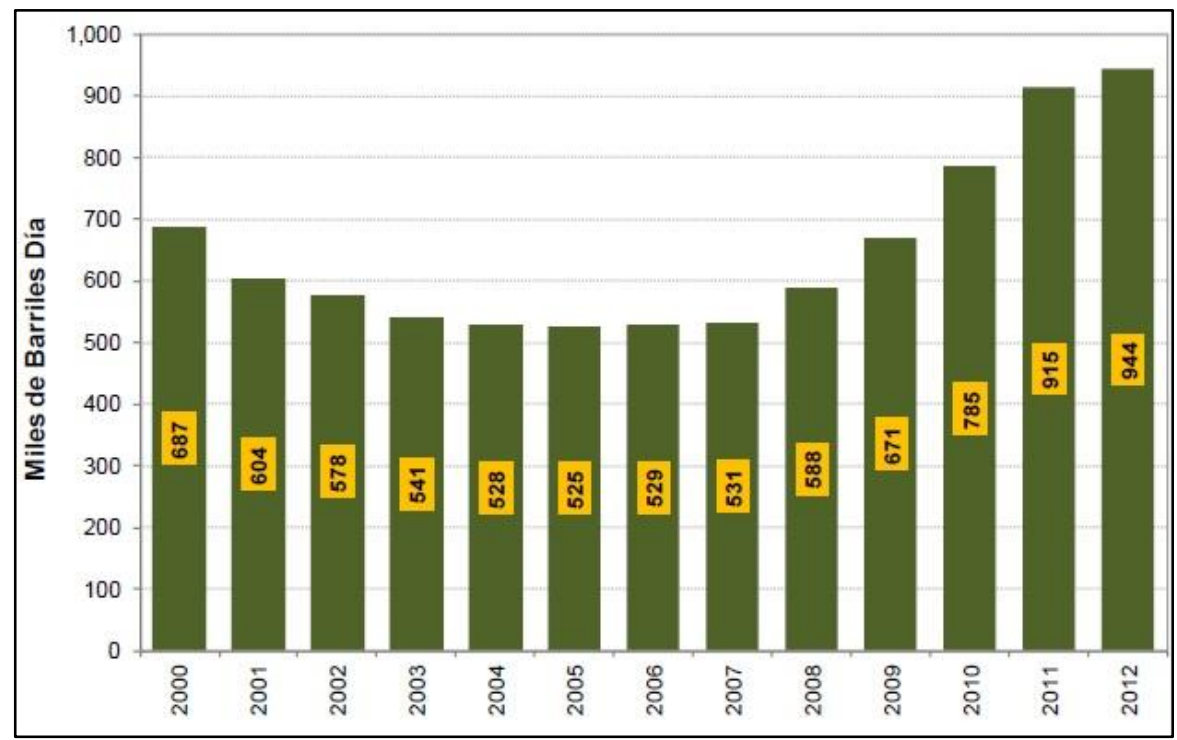

Fuente: Unidad de Planeación Minero Energética (2013)

Durante el primer quinquenio la producción se inició con 687 miles de barriles por día y mostró constante declinación hasta 2005, cuando llegó al mínimo de 525 miles de barriles por día. Desde el año 2006 se aprecia un continuo incremento hasta 2012, cuyo promedio diario anual se acerca a los 945 mil barriles por día, superando en 3,3 \% la producción de 2011 cuyo total fue de 914 mil barriles por día. Los campos con producción superior a 10.000 BPD se muestran en la Figura 3-15. 
Figura 3-15. Campos productores con producción mayor a 10.000 BPD

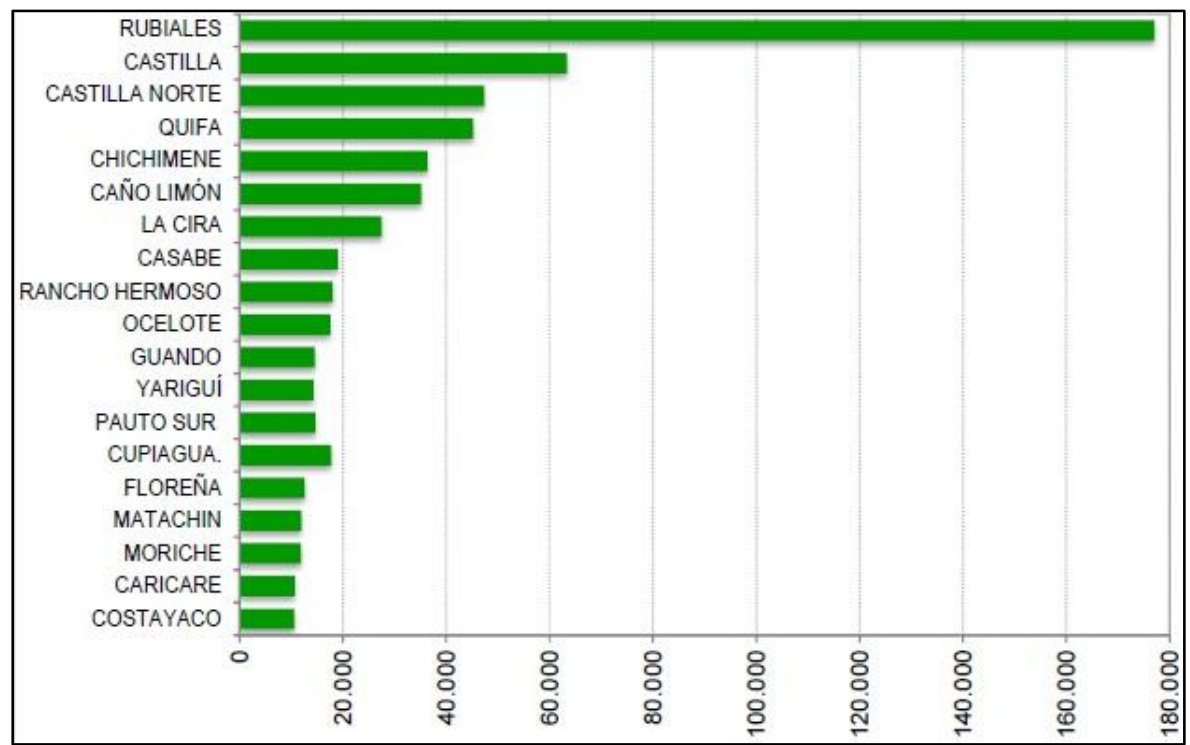

Fuente: Unidad de Planeación Minero Energética (2013)

Los campos de mayor producción son liderados por el campo Rubiales con una producción que llega al 18,8\% del total del país, seguido de Castilla con un participación del 6,7\%, Castilla Norte que llega a 5\%, Quifa a 4,8\% y Chichimene a 3,8\%, tal como lo muestra la Figura 3-15; todos estos cinco campos se localizan en el Departamento del Meta, cuenca de los Llanos Orientales. Los restantes 14 campos representan el 25\%. Estos cinco campos son responsables del 39,1\% del total del país, lo que explica que los esfuerzos exploratorios se realizan en esta cuenca, dadas las mayores probabilidades de éxito. En términos de empresas Ecopetrol S. A. cuenta con la mayor producción de crudo, alcanzando un 36,3\% del total nacional que equivale a 343,1 KBPD, seguida de la empresa Meta Petroleum Limited, que participa con el 23,8\% correspondiente a 224,6 KBPD y en tercer lugar se ubica Occidental de Colombia que aporta el 6,9\% significando 64,7 KBPD. (Unidad de Planeación Minero Energética, 2013)

Por su pate las cifras de exportación fueron las que se muestran en la Figura 3-16. 
Figura 3-16. Exportaciones e importaciones de petróleo

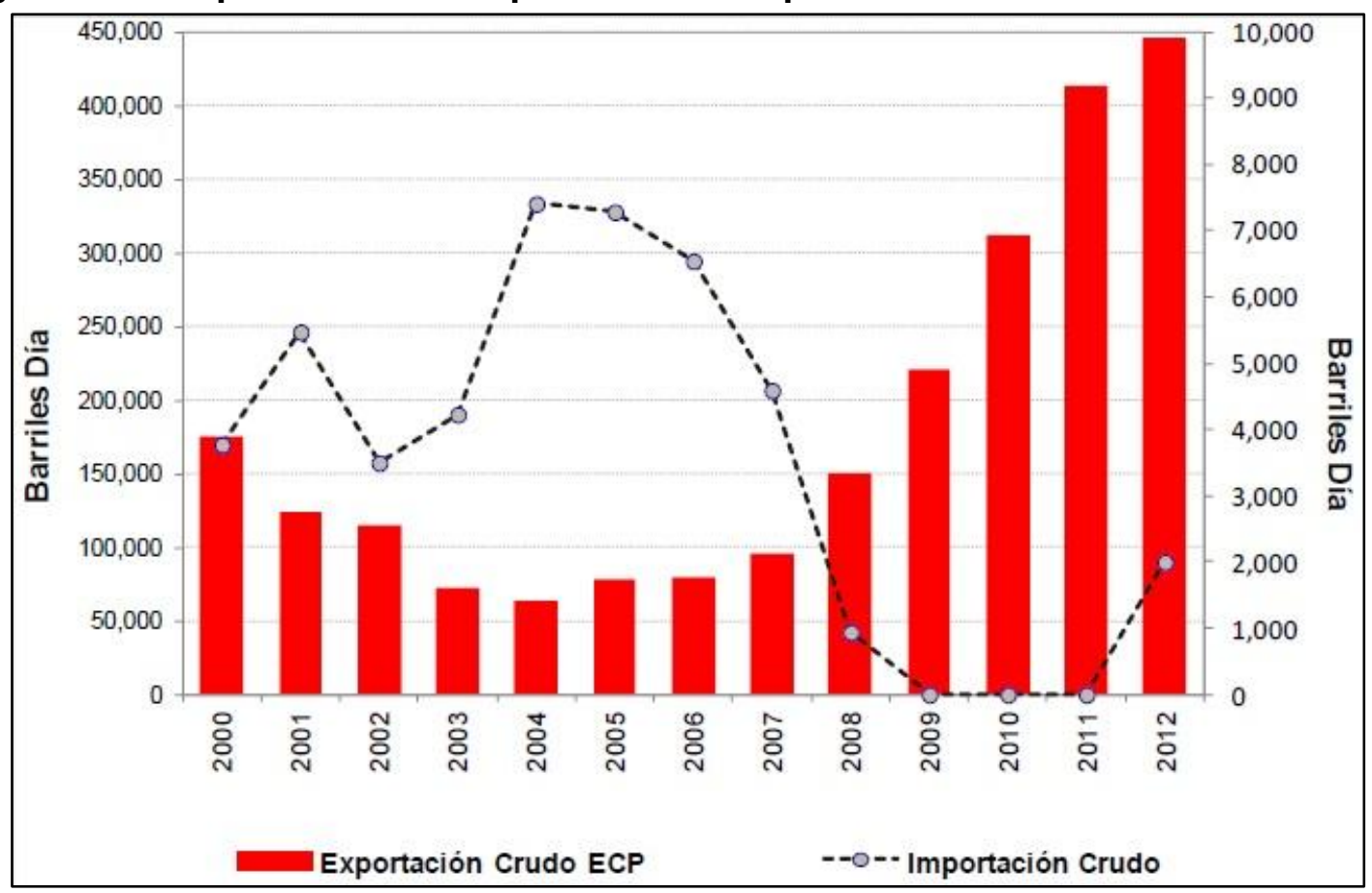

Fuente: Ecopetrol (2012)

Al finalizar 2012, las exportaciones totales de crudo alcanzaron un promedio de 622 mil barriles día, 4,1\% más que en 2011 cuando se llegó a 598 mil barriles día. La mezcla de crudo creció 62,2 puntos porcentuales con relación a la mezcla en 2000 y en promedio durante el período la tasa de crecimiento logró un 3,3\%, destacándose el 2004 como el año de menores exportaciones de crudo. Las divisas que generaron esas exportaciones fueron las que se muestran en la Figura 3-17. 
Figura 3-17. Evolución de las exportaciones de petróleo

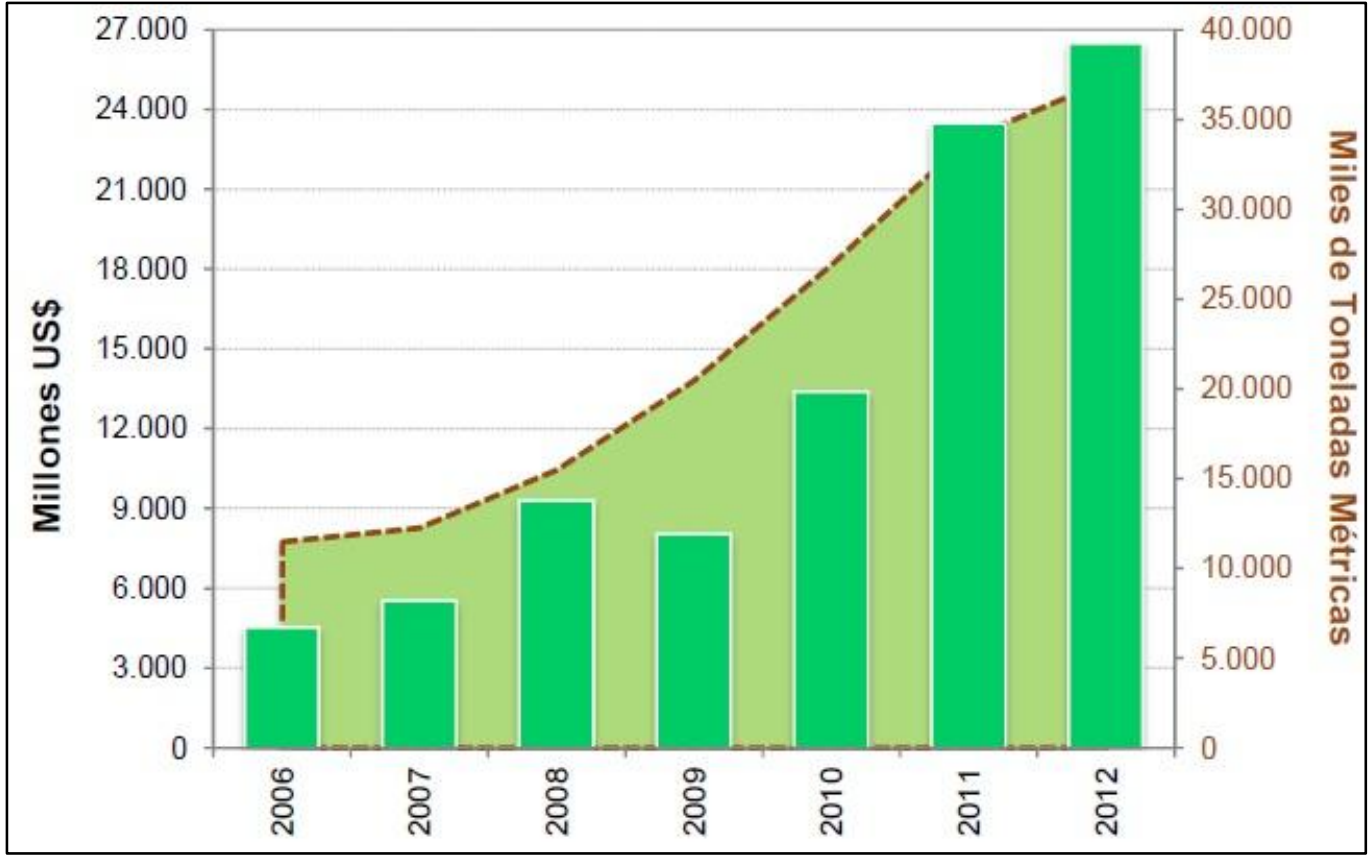

Fuente: DANE, DIAN (2012)

El ingreso de recursos creció en promedio durante los seis últimos años $39 \%$ y respecto al 2011 lo hizo al 13\%. Alusivo a los volúmenes, la tasa media de crecimiento en el período fue de $22 \%$ y respecto al 2011 aumentó 10\%, con lo cual se aprecia la importancia del sector en las finanzas públicas colombianas; esta información solo considera petróleo crudo.

Por su parte, entre 2006 y 2012 las importaciones crecieron 484\% en términos de dólares, en tanto que en términos de volumen aumentaron el $224 \%$ en el mismo periodo, pasando de 11.460 a 37.147 toneladas métricas. Se estima que este comportamiento se mantenga en los próximos años, teniendo en cuenta la prospectividad geológica colombiana y los precios internacionales de petróleo, además de los planes contractuales que se avecinan como consecuencia de los contratos suscritos productos de las distintas rondas realizadas por la Agencia Nacional de Hidrocarburos.

Al realizar un contrastes entre las Figuras $3-16$ y $3-17$, se puede inferir que en los periodos comprendidos entre el 2004 y el 2011, se presentó una marginalidad negativa 
creciente entre la importación de crudo, la cual es inversamente proporcional marginalmente a la exportación del mismo, sin embargo a partir del finales del año 2010 su marginalidad empieza a ser decreciente. 


\section{CONCLUSIONES}

El trabajo buscó evaluar la situación estratégica de la producción petrolera en Colombia. En primer lugar, como se pudo observar a lo largo de este trabajo, un hecho que determinó importantes efectos en este sector industrial fue la distribución de funciones de las diferentes entidades del gobierno relacionadas con el petróleo y concretamente la creación de la Agencia Nacional de Hidrocarburos en el año 2003; de hecho, los territorios dedicados a la exploración y explotación de hidrocarburos crecieron en más del 300\% y la producción superó por primera vez el millón de barriles en 2013.

El sector petrolero se halla vinculado tanto con el sector público, el sector externo y otros sectores y sus efectos se reflejan en los ingresos fiscales, la transferencia de las utilidades al Estado, la inversión extranjera directa, el comercio exterior, el pago de utilidades a las casas matrices extranjeras de las compañías que operan este sector en Colombia, el mercado cambiario, la demanda de mano de obra y la inflación, entre otros.

Se trata de un producto cuyo precio se ve permanentemente expuesto a la influencia de la situación de tensión o tranquilidad política que se vive en los países productores ubicados en diferentes regiones del planeta, dado que esa situación incide directamente en la oferta; esa influencia conduce a que inclusive se llegue a especular que algunas situaciones político-militares que se presentan en algunos países son en realidad estrategias cuyo verdadero propósito es influenciar el precio del crudo. Sin embargo para otros autores, los factores económicos tienen mayor importancia que los políticos, especialmente en los países que no hacen parte de la Organización de Países exportadores de petróleo, usando como base la Figura 2-2, se muestra que hubo una caída del precio del barril por debajo de los 20 dólares luego de los atentados del 11 de septiembre de 2001, luego de esto se observó una caída cercana a los 25 dólares a inicios del 2003 por la segunda guerra del golfo, de igual manera una caída de los 80 a los 60 dólares cuando se produce en el Líbano guerra entre Israel y Hezbolá a mediados del 2006, también se marca una variación a la baja caída entre los 65 y 50 dólares en la reelección del Presidente Hugo Chavez el 03 de diciembre de 2006, se presenta un pico con tendencia a la baja que en el 2008 donde el transitorio del precio pasa de los 110 a 
146 dólares y una abrupta caída por debajo de los 40 dólares entre la crisis de las hipotecas de alto riesgo en los Estados Unidos, hasta la quiebra de Lehman Brothers.

Entre tanto, en Colombia las políticas de contratación y las condiciones de los contratos de exploración y explotación son una de las situaciones que mayor efecto ejerce sobre la producción interna; así, cuando el Estado establece unas condiciones que favorecen la generación de utilidades y su traslado a los países en donde operan las compañías inversionistas, se observan procesos de crecimiento de la actividad petrolera; las políticas ambientales también tienen un efecto importante en la dinámica de esta industria, dado que para las empresas la claridad de esas políticas se refleja en la rapidez con la cual pueden proyectar la recuperación de sus inversiones. Por otro lado, la situación de orden público es un asunto de la mayor influencia en la industria del petróleo en Colombia, como quiera que desde hace varios años las fuerzas irregulares que operan en el país han protagonizado actos terroristas que han ocasionado importantes daños a la infraestructura petrolera, además de que han generado temor de sus empleados respecto de operar en zonas donde se presentan convulsiones de orden público en las que el riesgo de secuestros y atentados es alto.

Mientras que la oferta está entonces influenciada tanto internacionalmente como internamente por los factores mencionados, la demanda de crudo no ha parado de crecer a nivel mundial, y todavía no se vislumbran sustitutos reales que constituyan una amenaza importante para esta industria. Sin embargo existen expectativas de que se desarrollen cada vez nuevas opciones para las industrias de transporte y generación de energía, lo que a la larga puede generar un gran riesgo para el sector petrolero. Debido a los efectos que estos combustibles tienen en la producción de gases de efecto invernadero, en diferentes países se han venido realizando investigaciones que podrían en el mediano y largo plazo reducir las tasas de crecimiento de la demanda, y por lo tanto el precio. En la medida en que esa demanda decreciera, la economía de Colombia podría tener unos efectos muy notorios, dada la gran dependencia que la economía del país tiene de la continuidad en la generación de las divisas, los tributos y los empleos que caracterizan en la actualidad a este sector. 
Al mismo tiempo que los altos precios del crudo incrementan en el corto plazo la inversión extranjera directa que ingresa al país para generar unas utilidades que no se justifican cuando el precio es bajo, también se incrementa la amenaza de que surjan sustitutos más económicos y más amigables con el medio ambiente. Esta situación indica que el nivel de precios del petróleo tiene un nivel óptimo visto con una perspectiva de largo plazo, pues por encima de ese óptimo los efectos de corto plazo ponen en riesgo la sostenibilidad de la industria en el largo plazo; sin embargo no existe una cifra específica que permita definir cuál ese nivel óptimo de precio del petróleo.

Otro efecto de los precios altos de crudo es la incorporación de tecnologías orientadas a explotar reservas de petróleo que en otras circunstancias se desechan, debido a que esas tecnologías implican unos costos que hacen inviable su uso cuando los precios de venta son bajos. Igualmente los precios altos en Colombia hacen que se incrementen los costos de producción, si se tiene en cuenta que la mano de obra calificada para trabajar en este sector es limitada, por lo que escasea en la medida en que se desarrollan muchos proyectos de manera simultánea.

Por otro lado, la economía internacional y la situación del petróleo, así como sucede también a nivel interno en Colombia, tienen una gran interdependencia; de hecho, cuando las economía mundial se encuentra operando bajo condiciones normales de crecimiento, favorece a la situación del petróleo, pues la demanda crece para poder abastecer a más industrias, a más hogares y a más vehículos en el mundo. En cambio, cuando se presentan crisis como la que se experimentó en 2008 a escala mundial, el precio del petróleo es uno de los que primero se ve afectado.

La matriz de evaluación de factores externos de esta industria mostró que existen más oportunidades que amenazas, por lo que en la actualidad este sector en Colombia tiene mayores posibilidades de mantener su situación de éxito que de experimentar un receso. Debido a la escasez de grandes cantidades de capital y de la tecnología que demanda esta industria para su desarrollo, es que se origina la inversión extranjera directa que este sector requiere para mantener su dinámica, la cual es propiciada, entre otros aspectos, por la Ley 963 de 2005 en la que se establecen los denominados contratos de estabilidad jurídica. 
Entre los años 2000 a 2008 el consumo de petróleo ha sido el combustible fósil con menor tasa de crecimiento mundial de demanda, superada ampliamente por el crecimiento en la demanda de carbón mineral y gas natural y el petróleo Brent ha tenido un incremento de precio más acelerado que el de WTI, como consecuencia de la incertidumbre asociada al comportamiento de la economía mundial, a su vez generada por eventos geopolíticos, el crecimiento de la demanda en mercados emergentes, la lenta recuperación de la demanda de los países industrializados y la volatilidad de los mercados financieros. Igualmente las reservas mundiales presentaron un incremento en su crecimiento especialmente lento desde 2009 y hasta 2012 y los países de la OPEP siguen manteniendo el control de este mercado con el $72,6 \%$ de las reservas a nivel global.

En cambio la producción mundial tuvo un importante crecimiento entre 2009 y 2012 , especialmente concentrada en los países del medio oriente. Las mayores reservas de Latinoamérica se encuentran en Venezuela, Colombia, Brasil, Ecuador y Argentina y el hecho de que países vecinos a Colombia tengan reservas tan importantes, ha motivado a diferentes empresas a mantener o incrementar su inversión en proyectos de exploración en el país. A nivel interno los derivados del petróleo son la principal fuente de abastecimiento del sector transporte, que ha tenido un importante repunte del diésel como consecuencia del desarrollo de proyectos de transporte masivo en las grandes ciudades del país.

Las favorables condiciones de la economía mundial y la economía doméstica han propiciado el crecimiento de $400 \%$ en las inversiones entre 2005 y 2012 y con especial énfasis en esta industria, a pesar de que en 2009 hubo una desaceleración ocasionada por la recisión económica mundial. La destinación de un importante porcentaje de esas inversiones a proyectos de exploración, hace esperar que en los próximos años se incrementen las reservas nacionales de crudo, que en la actualidad son de 6,89 años con los ritmos de producción actuales.

La fase que mayor aceleración ha tenido ha sido la de producción, con un crecimiento de 77\% a partir de 2007 y hasta 2012 y el campo con mayor nivel de producción es el de Campo Rubiales, que concentra el $18,8 \%$ del total de la producción del país, aunque 
Ecopetrol mantiene el liderazgo en producción con el 36.3\% del total. La mayoría de ese crecimiento en la producción ha sido con destino a la exportación, que en 2012 llegó a un promedio diario de 622 mil barriles, mientras que las importaciones decrecieron de manera continua desde 2004 y hasta 2011. Ese crecimiento de las exportaciones hizo que el ingreso que el país recibe por ese concepto se incrementara hasta cerca de US\$25.000 millones en 2012.

Aunque no es sencillo resumir todo ese análisis en una sola frase, podría decirse que la producción de petróleo en el país va demasiado bien, al punto que un tropiezo en el precio mundial como consecuencia de algún fenómeno geopolítico imprevisto, pondría a la economía de todo el país en problemas, dado que esa producción se ha vuelto tan importante, que ha hecho que buena parte de la economía dependa de que el ritmo de producción y el nivel de precios se mantengan, lo que es la antesala a una crisis del gasto público. 


\section{Bibliografía}

Agencia Nacional de Hidrocarburos. (20 de Mayo de 2014). Agencia Nacional de Hidrocarburos, Historia. Obtenido de http://www.anh.gov.co: http://www.anh.gov.co/la-anh/Paginas/historia.aspx

Asamblea Nacional Constituyente. (1991). Constitución Política de Colombia 1991. Bogotá: Imprenta Nacional.

B. P., B. P. (2013). BP statistical review of world energy. Londres: Petroleum, British.

Banco de la República de Colombia. (2012). Borradores de Economía Núm 692. 2012. Obtenido de http://www.banrep.gov.co: http://www.banrep.gov.co/docum/ftp/borra692.pdf

Banco de la República de Colombia. (2013). La Economía Petrolera en Colombia (Partell) Relaciones Intersectoriales e importancia en la economia nacional. Obtenido de http://www.banrep.gov.co: http://www.banrep.gov.co/sites/default/files/publicaciones/archivos/be_748.pdf

Coleman, T. (2012). TENDENCIAS E IMPACTOS DE LA INVERSION EXTRANJERA DIRECTA EN COLOMBIA. Obtenido de http://repository.ean.edu.co: http://repository.ean.edu.co/bitstream/10882/1903/4/ColemanTasmaine2012.pdf

D’Alessio, F. (2008). El Proceso Estratégico: Un enfoque de gerencia. México: Pearson Educación.

DANE, D. A. (2012). Sector Minero y Petrolero en Colombia. Bogotá.

E. I. A., E. I. (2013). Evolución del Petróleo. Washington: E. I. A.

E.I.A. (2012). World Energy Outlook 2012. Wasingnton: E.I.A. 
Ecopetrol. (Marzo de 2014). Reporte de Gestión Sostenible 2013. Obtenido de http://www.ecopetrol.com.co:

http://www.ecopetrol.com.co/documentos/ecopetrol_2013.pdf

La Nota Económica. (2009). Ranking empresas de servicios petroleros de Colombia. Obtenido de La Nota: http://lanota.com/index.php/CONFIDENCIAS/Rankingempresas-de-servicios-petroleros-de-Colombia.html

Lajous, A. (2006). México: producción y reservas de petróleo y gas natural. Este País 186, 36-48.

Misiones On Line. (2007). El mundo acelera la búsqueda de los sustitutos del petróleo Documento electrónico. Obtenido de Eco2site: http://www.eco2site.com/informes/sustitutos.asp

Naciones Unidas CEPAL. (18 de Junio de 2013). LA CRISIS DE LOS PRECIOS DEL PETRÓlEO Y SU IMPACTO EN LOS PAÍSES CENTROAMERICANOS. Obtenido de http://www.eclac.cl: http://www.eclac.cl/publicaciones/xml/8/36328/L908.pdf

Perilla, R. (2009). El impacto de los Precios del Petróleo Sobre el Crecimiento Económico en Colombia. Obtenido de http://www.banrep.gov.co: http://www.banrep.gov.co/sites/default/files/eventos/archivos/Seminario35_0.pdf

Portafolio. (2010). Petroleras de América Latina necesitan aumentar inversión para subir producción, según calificadora. Obtenido de Portafolio: ttp://www.portafolio.com.co/archivo/documento/CMS-7693816

Porter, M. (1991). La ventaja competitiva de las naciones. Buenos Aires: Vergara Editor S. A.

Ramírez, J., \& Cuéllar, E. (Julio de 2013). Clúster del petróleo y el gas evaluación del entorno competitivo, agenda estratégica y elementos de una iniciativa de desarrollo del clúster. Bucaramanga. 
Ramírez, J., \& Cuéllar, E. (Julio de 2013). CLÚSTER DEL PETRÓLEO Y EL GAS EVALUACIÓN DEL ENTORNO COMPETITIVO, AGENDA ESTRATÉGICA Y ELEMENTOS DE UNA INICIATIVA DE DESARROLLO DEL CLÚSTER. Obtenido de http://gidrot.com/: http://gidrot.com/materials/docs/eyd/eyd3.pdf

Sánchez, E. (2010). SHOCKS DEL PRECIO DEL PETRÓLEO Y SU IMPACTO EN EL CRECIMIENTO Y LA INFLACIÓN DE LA ECONOMÍA COLOMBIANA. Obtenido de

http://www.bdigital.unal.edu.co: http://www.bdigital.unal.edu.co/6673/1/4074612010.pdf

Sánchez-Albavera, F., \& Vargas, A. (Septiembre de 2005). La volatilidad de los precios del petróleo y su impacto en América Latina. Obtenido de http://www.cepal.org: http://www.cepal.org/publicaciones/xml/9/22669/lcl2389e.pdf

Servicio Geológico Mexicano. (1 de Julio de 2014). Seguimiento precio del Petróleo WTI. Obtenido de http://portalweb.sgm.gob.mx/: http://portalweb.sgm.gob.mx/economia/es/energeticos/wti.html

Unidad de Planeación Minero Energética. (Febrero de 2005). La Cadena de Petróleo en Colombia. Obtenido de http://www.upme.gov.co: http://www.upme.gov.co/Docs/Cadena_Petroleo_2004.pdf

Unidad de Planeación Minero Energética. (2013). Cadena de Petróleo 2013. Bogotá: UPME. 